\title{
The coastal boundary layer: predictable current structure decreases alongshore transport and alters scales of dispersal
}

\author{
K. J. Nickols ${ }^{1,4, *}$, B. Gaylord ${ }^{1,2}$, J. L. Largier ${ }^{1,3}$ \\ ${ }^{1}$ Bodega Marine Laboratory, University of California at Davis, Bodega Bay, California 94923, USA \\ ${ }^{2}$ Department of Evolution and Ecology, and ${ }^{3}$ Department of Environmental Science and Policy, \\ University of California at Davis, Davis, California 95616, USA \\ ${ }^{4}$ Present address: Department of Wildlife, Fish and Conservation Biology, University of California at Davis, Davis, \\ California 95616, USA
}

\begin{abstract}
Dispersion of planktonic propagules connects shoreline populations of many marine species, and considerable effort has been directed at understanding this process. However, gaps in knowledge persist. In particular, relatively little information is available regarding transport over the innermost portions of the continental shelf. We quantified velocity in nearshore waters at 5 sites along the California coast and investigated flow patterns relevant for dispersing larvae and algal spores. Mean depth-averaged alongshore velocities increased with distance from shore at all sites. This repeated and consistent 'coastal boundary layer' (CBL) pattern exhibits a logarithmic profile that resembles that associated with the 'law of the wall' of smaller-scale turbulent boundary layers, despite differences in spatial dimension and governing physics. A tentative scaling of dominant terms in an alongshore momentum balance suggests nontrivial levels of lateral stress, but small cross-shore gradients in this quantity. Such a trend of near-constant lateral stress, when combined with simple representations of horizontal mixing (i.e. eddy viscosity parameterizations) that increase approximately linearly with distance from shore, provides a possible explanation for the observed logarithmic velocity pattern. Incorporating these cross-shore gradients in alongshore velocity and cross-shore mixing in a 2-dimensional particle-tracking simulation leads to a decrease in mean alongshore transport of larvae and an increase in the variance in dispersal distance. Most notably, the CBL is predicted to dramatically increase self-replenishment.
\end{abstract}

KEY WORDS: Coastal flow - Nearshore oceanography · Dispersal - Eddy diffusivity · Inner shelf · Larval transport · Self-recruitment · Self-replenishment · Open versus closed populations

Resale or republication not permitted without written consent of the publisher

\section{INTRODUCTION}

The coastal zone operates as a physical and biological interface between shoreline environments and waters offshore. It is within this region that most algal spores and larvae of benthic invertebrates and fish start and end their lives, nutrients are delivered to ecologically and economically important coastal ecosystems, and the bulk of anthropogenic inputs originate. Yet the oceanography of this region-especially the area beyond the surf zone but within a few kilometers of shore - is relatively poorly described. The resultant knowledge gap hinders progress in understanding flow-driven movement of organisms and other waterborne constituents, and inhibits research on associated population and community processes (Largier 2002).

The subject of propagule dispersal, including the transport of larval fish and invertebrates as well as algal spores, has attracted the attention of marine sci- 
entists for decades. As early as the middle of the last century, biologists recognized the role of larval delivery in driving patterns of population variability (Thorson 1946). The concept of supply-side ecology (Lewin 1986) yielded greater appreciation for the influence of oceanographic processes on larval recruitment and population dynamics (Gaines et al. 1985, Roughgarden et al. 1988). Ensuing work addressed the capacity for ocean currents to contribute to the establishment of species range limits and biogeographic pattern (Cowen 1985, Gaylord \& Gaines 2000). Research on the degree to which populations are self-seeding continues (Caley et al. 1996, Levin 2006), with considerable effort directed at quantifying population connectivity via oceanographic transport (Siegel et al. 2003, 2008, Paris et al. 2007).

In recent years, impetus has developed for understanding localized physical processes that affect transport close to shore. Rationale for this interest derives from increasing evidence, based on a variety of techniques (e.g. Hellberg et al. 2002, Thorrold et al. 2007, Jones et al. 2009), that self-recruitment of coastal populations can be appreciable, and that dispersal distances are often shorter than expected based on an organism's pelagic larval duration (Swearer et al. 2002, Palumbi 2004, Shanks 2009). Moreover, regions within a few kilometers from shore often have the highest abundance of larvae (Borges et al. 2007, Morgan et al. 2009, Shanks \& Shearman 2009). It is also recognized that dispersal in taxa like canopy-forming kelps, whose released spores remain viable in the water column for only a few days, is driven largely by nearshore flows (Gaylord et al. 2002, 2006). In some cases, explicit oceanographic mechanisms for the local retention of propagules have been identified, and these mechanisms are believed to enhance the return of larvae and spores to their natal site (e.g. island wakes, Swearer et al. 1999; headland wakes, Graham \& Largier 1997; embayments and other features, Wolanski 1992). Even in systems where agents of retention have not been conclusively demonstrated (Jones et al. 2005, Becker et al. 2007), the potential for reduced scales of dispersal is receiving greater consideration. Acquisition of information regarding the coastal physical environment therefore represents an important next step towards understanding propagule transport and population connectivity (Cowen \& Sponaugle 2009). Such information critically augments analogous data regarding larval behavior, which also plays a crucial role (Leis 2006, Morgan \& Fisher 2010).

Foreshadowed by work on island and headland wakes, an obvious, yet relatively unexplored place to look for physical mechanisms of reduced scales of dispersal is in the interaction of coastal flows with shoreline topography and bathymetry. As coastal currents transit along the continental shelf, frictional forces slow transport, producing a 'coastal boundary layer' (CBL), a feature first described in the Great Lakes (Csanady 1972). Although not always termed a $\mathrm{CBL}$, this decreased alongshore transport has since been quantified along sections of the east coast of the United States (Churchill 1985, Lentz et al. 1999) and along coasts of Australia (Wolanski 1992), as well as along the California margin (Hamilton et al. 2006). However, most measurements in this latter region have been confined to areas beyond the $30 \mathrm{~m}$ isobath (Lentz \& Winant 1986, Lentz 1994), missing inshore waters that may be critical for the dispersal of larvae and algal spores released into nearshore waters.

Zones of flow attenuation associated with the coastal boundary layer, while originating ultimately from increased bottom drag, are likely to also be influenced by bathymetry, shoreline topography, development of lateral shear, wave breaking and wave-current interactions, stratification and buoyancy flows, as well as the interplay of surface and bottom boundary layers which overlap in shallow water. Many of the above fluid dynamic processes are themselves the subject of study by the physical oceanographic community. Ongoing work includes refining estimates of nearshore mixing and dispersion (Clarke et al. 2007, Drake \& Edwards 2009, Ohlmann \& Mitarai 2010), dissecting how winds and waves drive inner-shelf circulation (Fewings et al. 2008, Lentz \& Fewings 2012), and quantifying drift and rip dynamics within the surf zone (Spydell et al. 2009, MacMahan et al. 2010). The complexity of this region is substantial, however, and progress towards a general understanding of coastal transport remains challenging. Even in highly resolved circulation models used to estimate patterns of larval connectivity (e.g. Mitarai et al. 2009), the finest scales of physical forcing are often not incorporated. Regional Ocean Modeling System (ROMS) analyses, for example, employ cells that are typically $600 \mathrm{~m}$ or more on a side and do not completely reach the shoreline (e.g. Rasmussen et al. 2009, Watson et al. 2010). Individual-based ecological models that integrate with circulation models (e.g. Gawarkiewicz et al. 2007, Werner et al. 2007) operate with similar limitations. Widely employed experimental techniques, such as high-frequency radar mapping of surface currents, likewise extend to within only 1 to $2 \mathrm{~km}$ of shore (Paduan \& Rosenfeld 1996, Kaplan \& Largier 2006). These spatial constraints significantly diminish the 
ability of scientists to predict dispersal patterns in taxa for which adult habitat is along the shoreline. Considerable advantages could therefore accrue from simple but robust parameterization schemes suitable for describing transport in the immediate vicinity of the coast.

Here we investigate general characteristics of nearshore currents and their potential to affect dispersal of propagules and other suspended materials. We focus on CBLs at multiple sites along the California coast, spanning a wide range of shoreline topographies and bathymetry. We describe a remarkably repeatable pattern in current velocity, discuss possible causes for this pattern, and present a first-order scaling analysis that points to a set of driving mechanisms consistent with observations. Lastly, we explore some implications of the CBL for propagule dispersal and marine population connectivity.
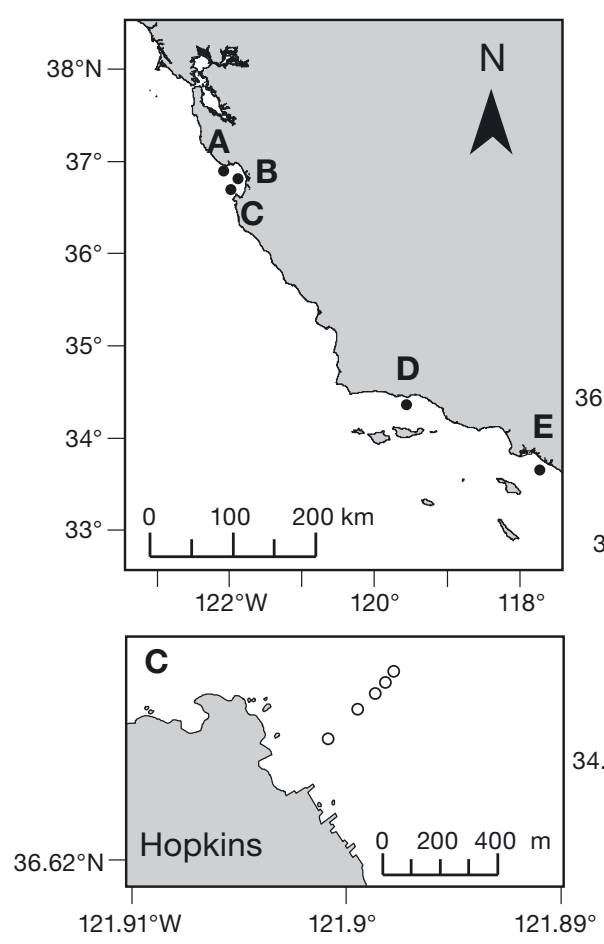

Fig. 1. Study area (top left) and (A-E) individual site maps. (o) Instrument locations

Table 1. Shoreline characteristics, deployment timelines, and analysis time periods for all sites. Slope is measured as depth increment per horizontal distance traversed. Orientation is measured as compass heading (degrees clockwise from North)

\begin{tabular}{|lcclc|}
\hline Site & Slope & Orientation & Deployment period & Segment analyzed \\
\hline Terrace Point & 0.023 & $286^{\circ}$ & Jul 1-Jul 23 2008 & 3 Jul-10 Jul 2008 \\
Hopkins & 0.044 & $142^{\circ}$ & 29 May-19 Jun 2008 & 29 May-5 Jun 2008 \\
Pajaro & 0.011 & $344^{\circ}$ & 30 Aug-23 Oct 2007 & 31 Aug-7 Sep 2007 \\
Mohawk & 0.033 & $278^{\circ}$ & 8 Jun-14 Jun 2007 & 9 Jun-14 Jun 2007 \\
Huntington Beach & 0.006 & $301^{\circ}$ & 19 Jul-12 Oct 2001 & 19 Jul-26 Jul 2001 \\
\hline
\end{tabular}

Inner shelf currents were characterized at 5 sites along the California coast, spanning a range of bathymetric slopes and degree of shoreline sinuosity (Fig. 1, Table 1). Two sites are located within the Southern California Bight: Huntington Beach $\left(33^{\circ} 37^{\prime} 36^{\prime \prime} \mathrm{N}, 117^{\circ} 59^{\prime} 13^{\prime \prime} \mathrm{W}\right)$ is an open-coast site characterized by a gently sloping sandy beach and wide shelf (Hamilton et al. 2006), and Mohawk (34 $23^{\circ} 29^{\prime \prime} \mathrm{N}, 119^{\circ} 43^{\prime} 39^{\prime \prime} \mathrm{W}$ ) is a low-lying reef surrounded by sand within the Santa Barbara Channel (Gaylord et al. 2007). Within the Southern California Bight, upwelling is weak and intermittent (Winant \& Dorman 1997), and inner shelf circulation is influenced by meso-scale eddies in some areas (Bassin et al. 2005). Three other sites are located farther north. Hopkins $\left(36^{\circ} 37^{\prime} 19^{\prime \prime} \mathrm{N}, 121^{\circ} 53^{\prime} 55^{\prime \prime} \mathrm{W}\right)$ is a rocky reef in southern Monterey Bay, surrounded by sand with the steepest slope and the most complex shoreline of the 5 sites, and with Cabrillo Point located a few hundred meters to the west. Pajaro $\left(36^{\circ} 51^{\prime} 37^{\prime \prime} \mathrm{N}\right.$, $121^{\circ} 49^{\prime} 21^{\prime \prime} \mathrm{W}$ ) is a gently sloping, straight sandy beach situated $1 \mathrm{~km}$ north of a river of the same name
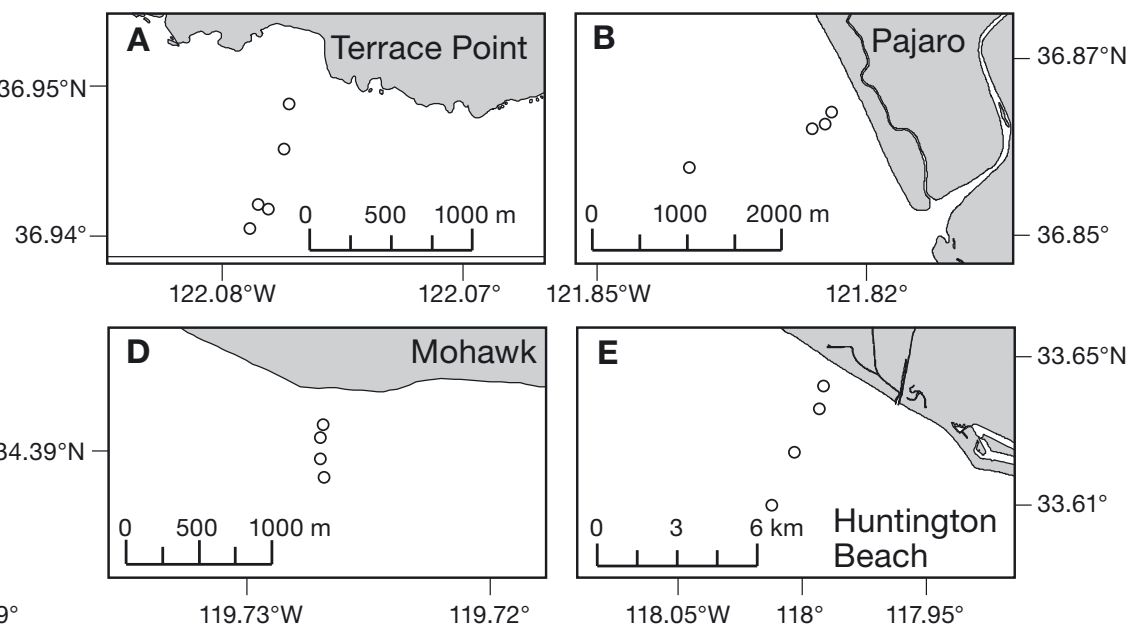
within Monterey Bay and $6.5 \mathrm{~km}$ north of the mouth of Monterey Canyon. Terrace Point (36 56' 36" N, $122^{\circ} 4^{\prime} 50^{\prime \prime} \mathrm{W}$ ) is a rocky bench on the open coast, surrounded by sand, and with small coves and minor headlands nearby. Upwelling influences the region surrounding Monterey Bay, although the local topography of each site modulates the response. For example, Terrace Point is at times fully exposed to upwelling but more usually found within an upwelling shadow, while Hopkins experiences topographic blockage from a minor headland. Mohawk, Hopkins, and Terrace Point have neighboring kelp forests. At all sites, depth increases roughly linearly with distance offshore.

\section{Current velocity measurements}

Water velocity was measured at each site using a transect of 4 to 5 bottom-mounted acoustic Doppler current profilers (ADCPs; RD Instruments $600 \mathrm{kHz}$, 1200 kHz; Nortek AWAC $1000 \mathrm{KHz}$ ) deployed in a cross-shore transect spanning 5 to $35 \mathrm{~m}$ depths and extending 190 to $5790 \mathrm{~m}$ from shore, depending on the bathymetric slope. The innermost instrument on each transect was placed 100 to $200 \mathrm{~m}$ beyond the surf zone, to exclude any significant effects due to wave-driven currents. All measurements were made in late spring or summer (Table 1). Deployments varied in duration from $1 \mathrm{wk}$ to 3 mo. For sites near kelp forests, ADCPs were typically located hundreds of meters away from the kelp beds, and all reef structures and even isolated kelp individuals were always $>10 \mathrm{~m}$ from the instruments. Measurements at Huntington Beach were obtained as part of a prior study (Noble \& Xu 2004, Hamilton et al. 2006).

The ADCPs collected 1 to 3 min bursts of $0.75 \mathrm{~Hz}$ velocity data every 2 or $3 \mathrm{~min}$ in vertical bins that typically extended from $\sim 1.5 \mathrm{~m}$ above the bottom to $\sim 1.5 \mathrm{~m}$ below the surface. Instruments deployed in $\leq 15 \mathrm{~m}$ water depth recorded in $0.5 \mathrm{~m}$ vertical bins, and those deployed in water depth $>15 \mathrm{~m}$ recorded in $1 \mathrm{~m}$ vertical bins. Exceptions from these protocols optimized tradeoffs in ADCP performance among vertical resolution, temporal resolution, depth range, and velocity estimate variance (Table 2). For shallower deployments, small vertical bins were necessary to resolve finer vertical velocity structure, whereas for deeper deployments where spatial gradients were gentler, larger bins increased the vertical extent of measurements and reduced noise. In the case of Huntington Beach, ADCP sampling methodology differed due to the distinct sampling goals of
Table 2. Sampling details of acoustic Doppler current profilers (ADCPs) for each site and instrument, including bottom depth where instruments were deployed (instrument depth), size of vertical bins (bin size), and the distance between the topmost valid profiler bin and the water's surface (distance to surface)

\begin{tabular}{|lccc|}
\hline Site & $\begin{array}{c}\text { Instrument } \\
\text { depth(s) }(\mathrm{m})\end{array}$ & $\begin{array}{c}\text { Bin size } \\
(\mathrm{m})\end{array}$ & $\begin{array}{c}\text { Distance to } \\
\text { surface }(\mathrm{m})\end{array}$ \\
\hline Mohawk & $7,11,15,20$ & 0.5 & 1.5 \\
Pajaro & $5,7,10$ & 0.5 & 1.5 \\
& 20 & 1 & 2.5 \\
Huntington Beach & 10,15 & 1 & 1.5 \\
& 25 & 1 & 4 \\
Hopkins & 35 & 2 & 8 \\
& 10,15 & 0.5 & 1.5 \\
Terrace Point & 20 & 1 & 1.5 \\
& 23,25 & 2 & 2.5 \\
& 10,15 & 0.5 & 1.5 \\
& $18,22,25$ & 1 & 1.5 \\
\hline
\end{tabular}

the prior study (Table 2). These differences have limited bearing on interpretations of this study, which are based on depth- and time-averaged velocities.

To quantify general patterns of the measured CBL circulation, the raw-velocity time series were depthaveraged and rotated onto their principal axes, which were determined from the low-pass filtered time series with a $33 \mathrm{~h}$ cutoff to remove dominant tidal motions (Rosenfeld 1983). In all cases, the major principal axis aligned roughly parallel to shore, defining the orientation of alongshore velocity $\left(U_{i}\right.$ see Table 3 for list of symbols). These depth-averaged velocities from each site were then further averaged over weekly durations to provide a focal data set relevant for considering transport of algal spores or larvae with relatively short pelagic larval durations, or for evaluating impacts on initial phases of transport in species with longer-dispersing larvae. In these more detailed analyses, core statistics were determined over the first week at each site for which complete records were available at all stations (Table 1). At Mohawk, the velocity record was $6 \mathrm{~d}$ long and velocities were averaged over the deployment duration.

\section{RESULTS}

\section{Field observations}

Depth-averaged currents were polarized in the alongshore direction at all stations, causing flows to be oriented predominantly parallel to the coast (Fig. 2, Table 4). Alongshore velocity magnitudes 
Table 3. List of symbols used in the paper

\begin{tabular}{|c|c|c|c|c|c|}
\hline Symbol & SI unit & Definition & Symbol & SI unit & Definition \\
\hline a & - & Coefficient of horizontal eddy & $U_{* \mathrm{CBL}}$ & $\mathrm{m} \mathrm{s}^{-1}$ & CBL-scale friction velocity \\
\hline \multirow[t]{2}{*}{$b$} & \multirow[t]{2}{*}{-} & $\begin{array}{l}\text { viscosity profile } \\
\text { Intercept from regression of the }\end{array}$ & \multirow{2}{*}{$\begin{array}{l}u^{\prime} \\
U_{\text {calc }}\end{array}$} & $\mathrm{m} \mathrm{s}^{-1}$ & $\begin{array}{l}\text { Depth-averaged alongshore velocity } \\
\text { residual }\end{array}$ \\
\hline & & $\begin{array}{l}\text { natural logarithm of distance from } \\
\text { shore against alongshore velocity }\end{array}$ & & $\mathrm{m} \mathrm{s}^{-1}$ & Depth-averaged alongshore velocity \\
\hline \multirow[t]{2}{*}{ C } & \multirow[t]{2}{*}{-} & \multirow{2}{*}{$\begin{array}{l}\text { Slope from regression of depth- } \\
\text { averaged velocity against bottom } \\
\text { velocity }\end{array}$} & & & of the law of the wall \\
\hline & & & $V$ & $\mathrm{~m} \mathrm{~s}^{-1}$ & Depth-averaged cross-shore velocity \\
\hline$d$ & - & $\begin{array}{l}\text { Exponent of horizontal eddy } \\
\text { viscosity profile }\end{array}$ & $V^{\prime}$ & $\mathrm{m} \mathrm{s}^{-1}$ & $\begin{array}{l}\text { Depth-averaged cross-shore velocity } \\
\text { residual }\end{array}$ \\
\hline \multirow{2}{*}{$D$} & \multirow{2}{*}{$\mathrm{Pa}$} & \multirow{2}{*}{$\begin{array}{l}\text { Integration constant in lateral stress } \\
\text { profile equation }\end{array}$} & $x$ & $\mathrm{~m}$ & Alongshore position \\
\hline & & & y & $\mathrm{m}$ & $\begin{array}{l}\text { Distance from shore (cross-shore } \\
\text { position) }\end{array}$ \\
\hline$h$ & $\mathrm{~m}$ & Water depth & & & Cosition) \\
\hline$K_{Y}$ & $\mathrm{~m}^{2} \mathrm{~s}^{-1}$ & Horizontal eddy viscosity & $y_{0}$ & $\mathrm{~m}$ & $\begin{array}{l}\text { CBL-Scale horlzontal roughness } \\
\text { parameter }\end{array}$ \\
\hline$K_{z}$ & $\mathrm{~m}^{2} \mathrm{~s}^{-1}$ & Vertical eddy viscosity & $Z$ & $\mathrm{~m}$ & Vertical distance from seafloor \\
\hline \multirow[t]{2}{*}{$m$} & \multirow[t]{2}{*}{-} & \multirow{2}{*}{$\begin{array}{l}\text { Slope from regression of the natural } \\
\text { logarithm of distance from shore } \\
\text { against alongshore velocity }\end{array}$} & $z_{0}$ & $\mathrm{~m}$ & Vertical roughness height \\
\hline & & & $\alpha$ & - & Bathymetric slope \\
\hline$P$ & $\mathrm{~Pa}$ & Pressure & $\begin{array}{l}\kappa \\
\rho\end{array}$ & $\mathrm{kg} \mathrm{m}^{-3}$ & $\begin{array}{l}\text { von Karman's constant } \\
\text { Mass density of fluid }\end{array}$ \\
\hline$r$ & $\mathrm{~m} \mathrm{~s}^{-1}$ & Linear drag coefficient & $\tau$ & $\mathrm{Pa}$ & Shear stress \\
\hline$u$ & $\mathrm{~m} \mathrm{~s}^{-1}$ & Depth-specific alongshore velocity & $\tau_{0}$ & $\mathrm{~Pa}$ & Wall shear stress (bottom stress) \\
\hline$U$ & $\mathrm{~m} \mathrm{~s}^{-1}$ & Depth-averaged alongshore velocity & $\tau_{\mathrm{b}}$ & $\mathrm{Pa}$ & Bottom stress \\
\hline \multirow[t]{2}{*}{$u_{*}$} & \multirow[t]{2}{*}{$\mathrm{m} \mathrm{s}^{-1}$} & \multirow{2}{*}{$\begin{array}{l}\text { Friction velocity based on bottom } \\
\text { shear }\end{array}$} & $\tau_{\text {lat }}$ & $\mathrm{Pa}$ & Lateral stress \\
\hline & & & $\tau_{\mathrm{s}}$ & $\mathrm{Pa}$ & Surface wind stress \\
\hline
\end{tabular}
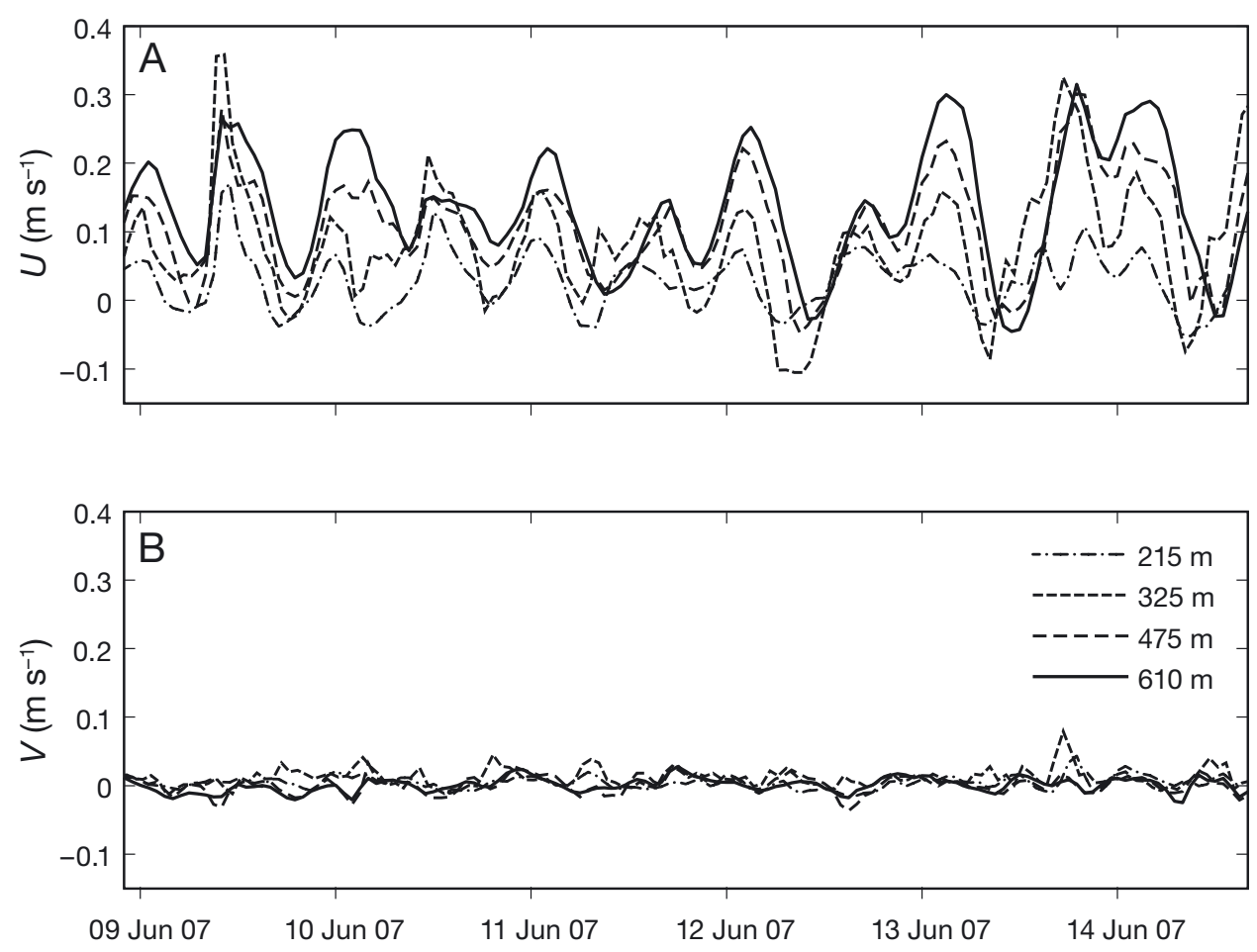

Fig. 2. Unfiltered time series of depth-averaged (A) alongshore, $U$, and (B) cross-shore, $V$, velocity recorded at Mohawk, at several distances from shore. Patterns of polarized flow in the alongshore direction and decreased velocity magnitude with decreased distance from shore were common amongst sites 
Table 4. Mean and standard deviation (SD) of depth-averaged alongshore $(U)$ and cross-shore $(V)$ velocity magnitudes recorded over a $1 \mathrm{wk}$ period. Units are in $\mathrm{m} \mathrm{s}^{-1}$. Stations within a site are listed by distance from shore and depth in $\mathrm{m}$

\begin{tabular}{|c|c|c|c|c|c|}
\hline \multirow[t]{2}{*}{ Site } & \multirow{2}{*}{$\begin{array}{c}\text { Distance } \\
\text { (depth) }\end{array}$} & \multicolumn{2}{|c|}{ Mean } & \multicolumn{2}{|c|}{$\mathrm{SD}$} \\
\hline & & $U$ & V & $U$ & $V$ \\
\hline \multirow[t]{4}{*}{ Mohawk } & $215(7)$ & 0.0295 & 0.0019 & 0.0084 & 0.0042 \\
\hline & 325 (11) & 0.0737 & 0.0068 & 0.0351 & 0.0021 \\
\hline & 475 (15) & 0.1053 & 0.0050 & 0.0233 & 0.0038 \\
\hline & $610(20)$ & 0.1260 & 0.0087 & 0.0265 & 0.0037 \\
\hline \multirow[t]{4}{*}{ Pajaro } & 325 (5) & 0.0163 & 0.0130 & 0.0234 & 0.0068 \\
\hline & $385(7)$ & 0.0220 & 0.0081 & 0.0453 & 0.0053 \\
\hline & 540 (10) & 0.0565 & 0.0017 & 0.0152 & 0.0027 \\
\hline & $1870(20)$ & 0.0774 & 0.0020 & 0.0282 & 0.0052 \\
\hline \multirow{4}{*}{$\begin{array}{l}\text { Huntington } \\
\text { Beach }\end{array}$} & 835 (10) & 0.0332 & 0.0037 & 0.0305 & 0.0036 \\
\hline & 1755 (15) & 0.0847 & 0.0047 & 0.0615 & 0.0073 \\
\hline & 3605 (25) & 0.1529 & 0.0118 & 0.0626 & 0.0151 \\
\hline & $5790(35)$ & 0.1625 & 0.0329 & 0.0158 & 0.0195 \\
\hline \multirow[t]{5}{*}{ Hopkins } & 195 (10) & 0.0012 & 0.0089 & 0.0036 & 0.0033 \\
\hline & 340 (15) & 0.0062 & 0.0038 & 0.0072 & 0.0018 \\
\hline & $415(20)$ & 0.0145 & 0.0017 & 0.0162 & 0.0029 \\
\hline & $470(23)$ & 0.0301 & 0.0026 & 0.0234 & 0.0040 \\
\hline & 570 (25) & 0.0427 & 0.0016 & 0.0308 & 0.0056 \\
\hline \multirow{5}{*}{$\begin{array}{l}\text { Terrace } \\
\text { Point }\end{array}$} & 300 (10) & 0.0133 & 0.0029 & 0.0047 & 0.0058 \\
\hline & 560 (15) & 0.0489 & 0.0007 & 0.0167 & 0.0028 \\
\hline & 910 (18) & 0.0782 & 0.0016 & 0.0326 & 0.0060 \\
\hline & $930(22)$ & 0.0791 & 0.0005 & 0.0318 & 0.0051 \\
\hline & $1100(25)$ & 0.0745 & 0.0022 & 0.0358 & 0.0045 \\
\hline
\end{tabular}

generally exceeded cross-shore magnitudes by a factor of 10, a pattern seen elsewhere in nearshore velocity records (e.g. Gaylord et al. 2007). Most importantly, weekly averaged alongshore current speeds were consistently slower at shallower stations nearer the coast (Fig. 3, Table 4). For example, amongst our 5 sites, velocities at the offshore edge of the transects ranged from $0.043 \mathrm{~m} \mathrm{~s}^{-1}$ at Hopkins to $0.16 \mathrm{~m} \mathrm{~s}^{-1}$ at Huntington Beach, and velocities at the innermost stations ranged from $0.0012 \mathrm{~m} \mathrm{~s}^{-1}$ at Hopkins to $0.033 \mathrm{~m} \mathrm{~s}^{-1}$ at Huntington Beach (Figs. 3 \& 4, Table 4).

The increase in depth-averaged alongshore velocity with distance from shore closely followed a logarithmic pattern in most cases (Fig. 4). Logarithmic profiles at Mohawk, Terrace Point, and Huntington Beach fit the depth- and time-averaged field data strikingly well (Fig. 4A,D,E). At Hopkins, the logarithmic model did not hold, but the general trend of increasing velocity with distance was reproduced (Fig. 4C). At Pajaro, the velocity gradient was relatively poorly defined due to how data points were clustered; however, a logarithmic relationship between velocity and distance from shore fit better than a linear relationship (Fig. $4 \mathrm{~B}_{;} \mathrm{r}^{2}=0.85$ versus 0.74 ).
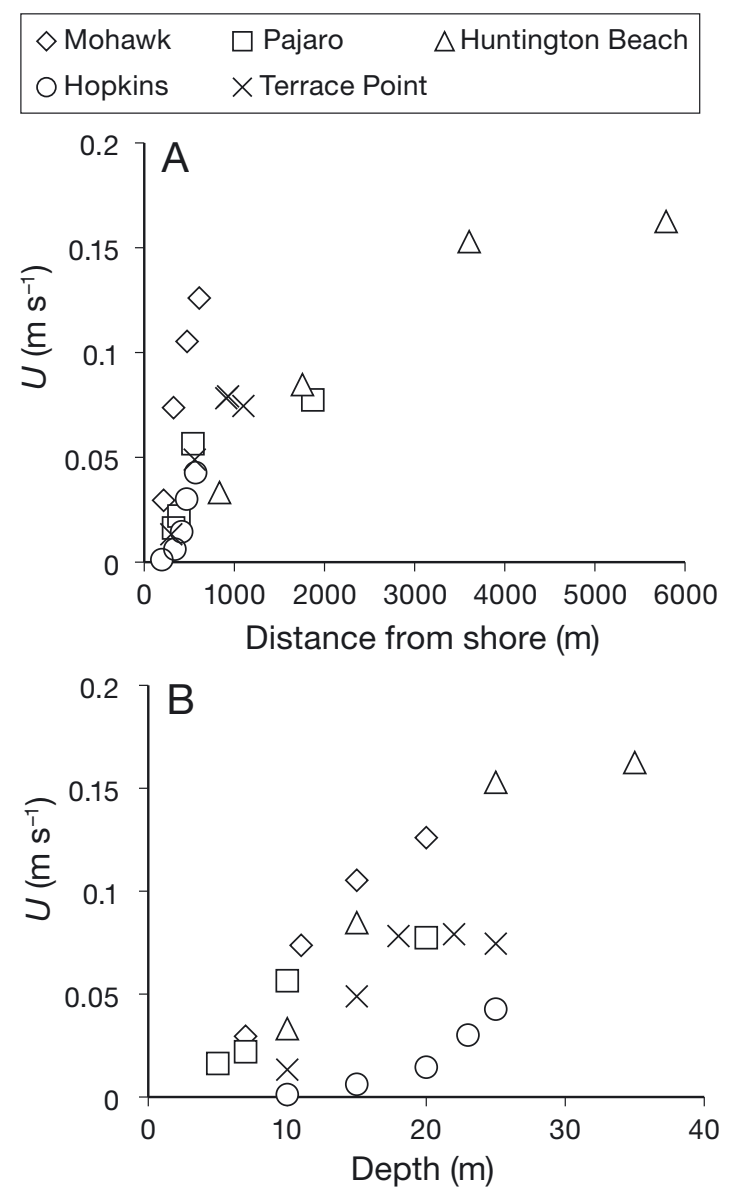

Fig. 3. Week- and depth-averaged alongshore velocity, $U$, for all sites plotted against (A) distance from shore, and (B) depth

\section{The coastal boundary layer profile}

A logarithmic flow pattern in the CBL is reminiscent of velocity profiles in small-scale turbulent boundary layers governed by the universal 'law of the wall' (Schlicting 1979). In the law-of-the-wall model, velocities parallel to a boundary increase logarithmically with distance from that boundary according to:

$$
\frac{u(z)}{u_{*}}=\frac{1}{\kappa} \ln \left(\frac{z}{z_{0}}\right)
$$

where along-wall velocity $u$ is normalized by the friction velocity $u_{*}=\sqrt{\frac{\tau_{0}}{\rho}}$ (where $\tau_{0}$ is the wall shear stress and $\rho$ is the mass density of the fluid), the distance from the wall $z$ is normalized by a roughness parameter $z_{0}$, and von Karman's constant $\kappa$ is set to 0.4 .

The parameters underlying the law of the wall do not apply directly to the CBL where different physi- 

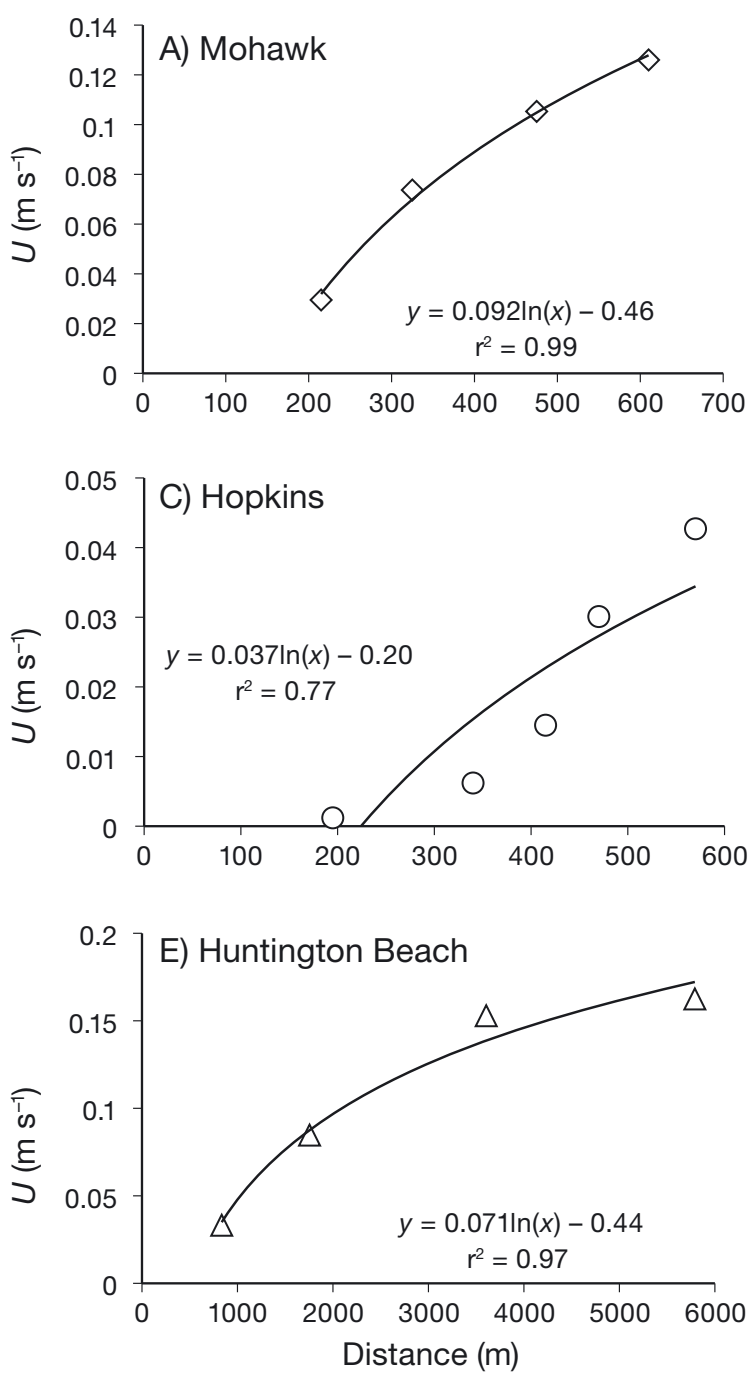

cal processes are active and scales of motion are orders of magnitude larger than for turbulence. On the other hand, the law of the wall formulation provides a convenient mathematical shorthand for representing the CBL structure. Using Eq. (1) as an analogy, cross-shore profiles of depth-averaged alongshore velocity can be plotted for each site as a function of distance from shore $(y)$ according to the expression:

$$
\frac{U(y)}{U{ }^{*} \mathrm{CBL}}=\frac{1}{\kappa} \ln \left(\frac{y}{y_{0}}\right)
$$

where $U$ is the depth- and time-averaged alongshore component of velocity, and $U_{{ }^{*} \mathrm{CBL}}$ and $y_{0}$ represent CBL-scale analogs of the friction velocity and roughness parameters, respectively. These latter 2 parameters can be calculated for each site from the slope $(m)$ and intercept $(b)$ of the linear regression of depth- and time-averaged alongshore
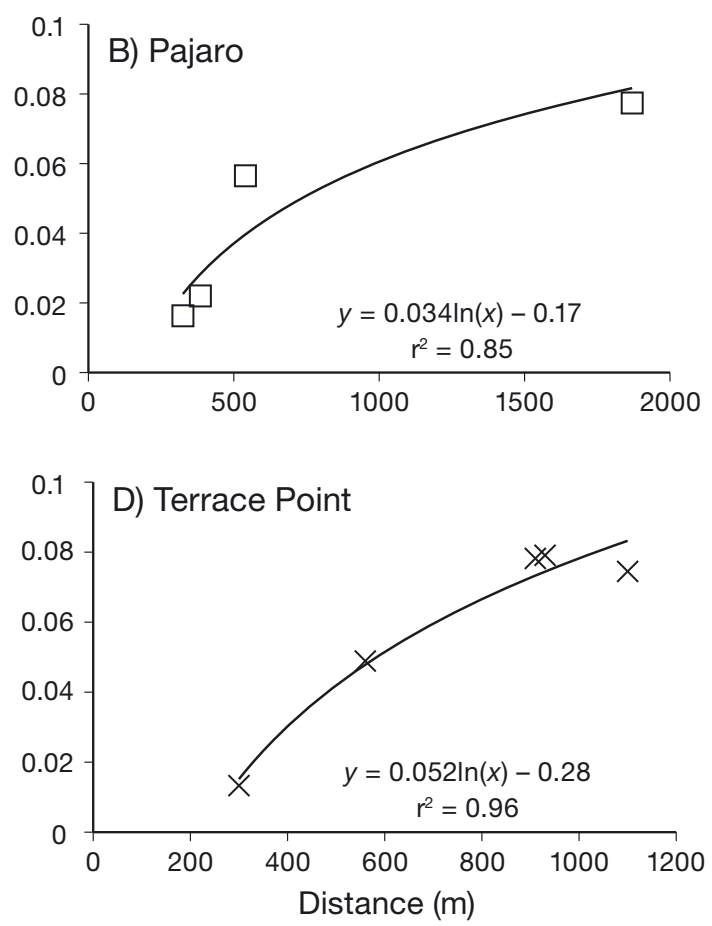

Fig. 4. Depth- and time-averaged alongshore velocity, $U$, profiles for each site (A-E) as a function of distance from shore. Solid lines show the associated best-fit logarithmic relationships for each site

velocity $(U)$ plotted against the natural logarithm of distance from shore $(y)$ :

$$
\begin{gathered}
U_{*_{\mathrm{CBL}}}=\kappa m \\
y_{0}=\mathrm{e}^{\left(\frac{-b}{m}\right)}
\end{gathered}
$$

Normalizing the velocity and distance data by sitespecific $U_{{ }^{*} \mathrm{CBL}}$ and $y_{0}$ values, respectively, and assembling these data across sites, reveals a remarkably consistent trend. Plots of alongshore velocity, $U$, versus the natural logarithm of distance from shore, $y_{\text {, }}$ from all sites collapse to a single straight line (Fig. 5). This apparently general relationship holds in spite of appreciable bathymetric and topographic differences among sites.

Across the 5 sites, values of $U_{{ }^{*} \mathrm{CBL}}$ ranged from 0.014 to $0.037 \mathrm{~m} \mathrm{~s}^{-1}$, and values of $y_{0}$ ranged from 150 to $510 \mathrm{~m}$. As might be expected, these CBL parameter values differed in character from friction veloc- 


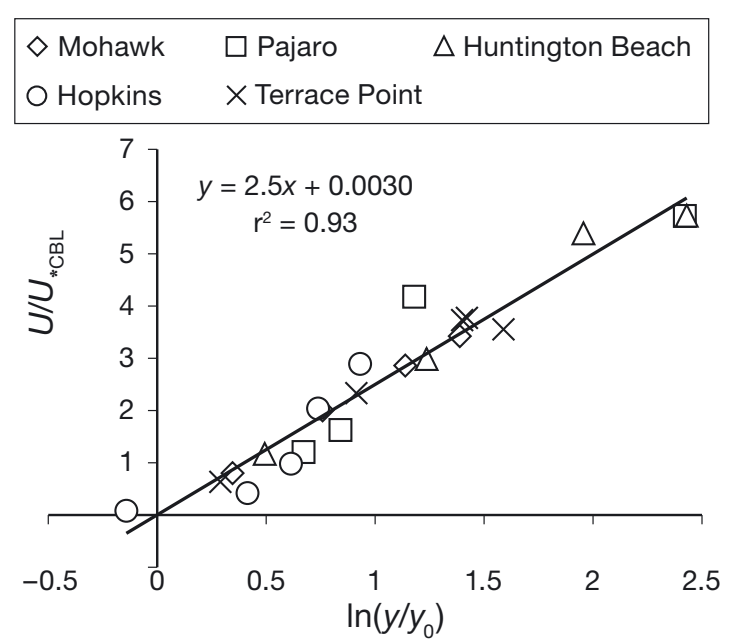

Fig. 5. The law of the wall applied to coastal boundary layers. Note the collapse of all data to a single straight relationship when graphed as a semi-log plot. On the abscissa, distance from shore $y$ is normalized by a coastal boundary layer (CBL)-scale horizontal roughness parameter, $y_{0}$. On the ordinate, depth-averaged alongshore velocity, $U$, is normalized by a CBL-scale friction velocity, $U_{*^{*} \mathrm{CBL}}$. These 2 parameters were determined using Eq. (2)

ities and roughness heights measured in small-scale benthic boundary layers. For example, values of $U_{{ }^{*} \mathrm{CBL}}$ were 17 to $35 \%$ of the velocity farthest from the shore (taken as the free-stream velocity), whereas values of $u_{*}$ measured in benthic boundary layers are typically only 5 to $10 \%$ of the free-stream velocity (Grant \& Madsen 1986, Denny 1988). These differences suggest that a greater relative 'wall' drag is imposed by the complex and shoaling boundary in the CBL. In addition, values of $y_{0}$ were 2 to 4 orders of magnitude larger than roughness lengths characterizing benthic boundary layers, consistent with the larger scales of the CBL and the topographic irregularity of the shoreline, as well as the cross-shore scale of the wave-dominated surf zone.

\section{Consistency of the CBL profile through time}

A logarithmic trend to the CBL was particularly apparent during periods of slowly varying (i.e. quasisteady) alongshore flow. By contrast, this pattern degenerated periodically during current reversals or marked changes in the large-scale flow (Fig. 6A-C). Considering a sequence of $1 \mathrm{wk}$ averaging periods shifted forward in $1 \mathrm{~d}$ steps, a logarithmic pattern was present during all 14 of the averaging periods at Terrace Point (Fig. 6C), during $65 \%$ of the 80 averaging periods at Huntington Beach (Fig. 6A), and during $60 \%$ of the 13 averaging periods at Hopkins (Fig. 6B). The temporal consistency of the CBL pattern could not be determined at Mohawk and Pajaro due to shorter records or data gaps.

Although the logarithmic pattern persisted for weeks at a site, values of $U_{{ }^{*} \mathrm{CBL}}$ and $y_{0}$ at each site were not constant through time. Variation in these parameters was most pronounced at Huntington Beach (Fig. 6D,G), partly due to the diversity of flow conditions encountered over the longer deployment, as well as more pronounced reversals in the large-scale flow. However, at times when flow was quasi-steady (e.g. Days 52 to 62), $U_{*^{*} \mathrm{CBL}}$ and $y_{0}$ at Huntington Beach exhibited reduced variance, with values similar to those at Hopkins and Terrace Point $\left(U_{*_{\mathrm{CBL}}}\right.$ from 0.010 to $0.030 \mathrm{~m} \mathrm{~s}^{-1} ; y_{0}$ from 50 to $500 \mathrm{~m}_{i}$ Fig. 6D-I).

\section{DISCUSSION}

\section{Bottom drag}

The above observations demonstrate that depthaveraged alongshore currents near the coast exhibit a repeatable pattern analogous to the 'law of the wall' of small-scale boundary layers. The general trend of slower velocities nearer the shore is itself not surprising, emerging as an accompaniment to the increased importance of bottom drag in a shallower water column. On the other hand, the geometry of the CBL (shoaling bottom) differs significantly from that characterizing a 1-dimensional wall-bounded flow, making the logarithmic relationship of Fig. 5 less than intuitive. Below we demonstrate that while bottom friction can yield a logarithmic pattern in flow, it does not by itself explain this feature of the CBL.

The seabed within the CBL slopes upward to the shore such that a clear coastal 'wall' cannot be identified. Instead, friction is manifested through a distributed drag imposed over a region of finite crossshore extent. Within this region, bottom drag is expected to establish a vertically oriented bottom boundary layer at each cross-shore position, as described by Eq. (1) (e.g. Grant \& Madsen 1986, Eckman 1990, Gaylord et al. 2006). As this bottom boundary layer encompasses more of the water column in shallower depths, depth-averaged velocities are reduced closer to shore. Estimates of depth-averaged velocities, $U_{\text {calc, }}$ at given distances from shore, $y$, can be found by integrating Eq. (1) and dividing the result by the total water column depth, $h$ :

$$
U_{\text {calc }}(y)=\frac{1}{h} \int_{z_{0}}^{h} \frac{U_{*}}{\kappa} \ln \left(\frac{z}{z_{0}}\right) \mathrm{d} z
$$



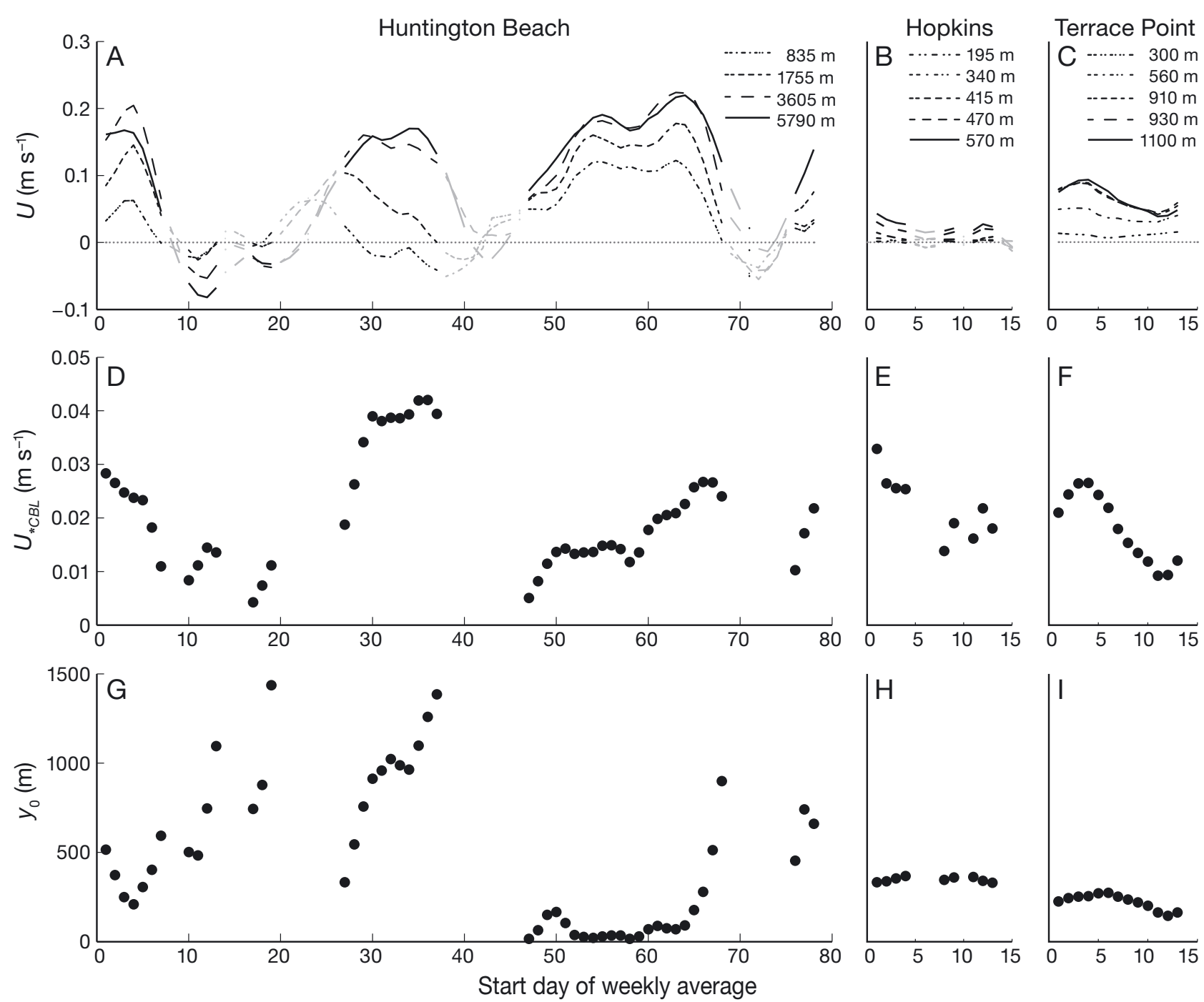

Fig. 6. Week-long means of depth-averaged alongshore velocity, $U$, at each cross-shore station for (A) Huntington Beach, (B) Hopkins, and (C) Terrace Point with corresponding values for (D-F) $U_{*_{\mathrm{CBL}}}$ and (G-I) $y_{0}$ calculated from logarithmic cross-shore profiles. Successive estimates of the week-long mean are advanced in $1 \mathrm{~d}$ steps, and individual points are removed in (A-C) for clarity. Decreasing dash-length (in Panels A, B, C) indicates increasing proximity to the shoreline; gray values indicate periods when the cross-shore velocity profiles were not logarithmic. Zero velocity in $(\mathrm{A}-\mathrm{C})$ is indicated for reference using a dotted line

where $h=y \tan \alpha$ and $\alpha$ is the bathymetric slope. Completing this mathematical operation yields (see Appendix 1):

$$
U_{\text {calc }}(y)=\frac{u_{*}}{\kappa}\left[\ln \left(\frac{y \tan \alpha}{z_{0}}\right)-1\right]+\frac{u_{*} Z_{0}}{\kappa y \tan \alpha}
$$

In coastal waters where $y>z_{0}$ this expression approaches a logarithmic form in the $y$-dimension, indicating that a logarithmic bottom boundary layer (i.e. in the $z$-direction) acting over a linearly sloping seabed can indeed produce a near-logarithmic crossshore profile in depth-averaged alongshore flow. Critically, however, values of bottom roughness $\left(z_{0}\right)$ that would be required to reproduce the observed CBL gradient (i.e. $U_{\text {calc }}[y]$ ) are too large to be physically reasonable. For example, at Mohawk, a value of $z_{0}=3.0 \mathrm{~m}$ would be required to fit Eq. (5) to the field data. Such roughness levels exceed typical values of $z_{0}$ by over an order of magnitude, even when considering events of high bottom stress and accounting for wave-current interaction (Wiberg et al. 1994). Conducting the opposite analysis reveals an analogous mismatch. Predicting a CBL from Eq. (5) using values of bottom stresses and roughness heights reasonable for benthic boundary layers $\left(z_{0}=0.1\right.$ and $u_{*}=5 \%$ of free-stream velocity $=0.0063 \mathrm{~m} \mathrm{~s}^{-1}$ for Mohawk) 


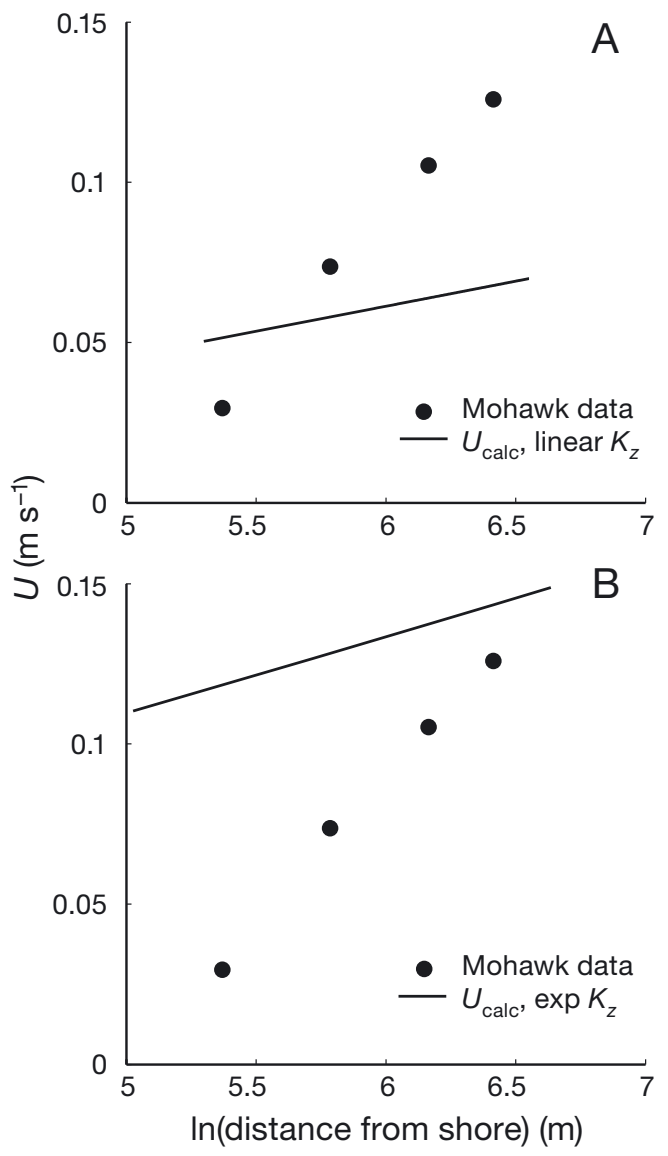

Fig. 7. Mismatch between field-measured, depth-averaged velocity $(U, \bullet)$ and modeled depth-averaged velocity based on a simple vertical integration of a benthic boundary layer. (A) Mismatch resulting from the use of realistic values of $u_{*}$ and $z_{0}$ to compute $U_{\text {calc }}$ assuming a linear vertical eddy viscosity profile (solid line). (B) Mismatch present after incorporating an exponential vertical eddy viscosity profile (solid line). Results are for Mohawk, but are consistent across sites

yields profiles with unrealistically weak velocity gradients (Fig. 7A). Similar or greater discrepancies were found for all sites.

We can further explore this idea by using different descriptions for vertical mixing. Implicit to Eqs. (1), (4), \& (5) is the assumption that vertical mixing can be approximated by a linear 'eddy viscosity' (Grant \& Madsen 1986), defined as $K_{z}=\kappa u_{*} z$, where $K_{z}$ is related to shear stress $(\tau)$ and the vertical velocity gradient by:

$$
\tau=\rho K_{z} \frac{\mathrm{d} u}{\mathrm{~d} z}
$$

An alternative form for eddy viscosity that is often employed in marine systems is (Eckman 1990, Gaylord et al. 2006):

$$
K_{z}=\kappa u_{*} z \exp \left(\frac{-2 z}{h}\right)
$$

Integrating Eq. (6) numerically using this latter form for $K_{z}$ together with reasonable values for $\tau_{0}$ $(0.1 \mathrm{~Pa})$ and $z_{0}(0.1 \mathrm{~m})$, again reveals that bottom stress alone cannot explain the observed CBL profile (Fig. 7B). Regardless of the model of vertical mixing, and for all sites, the cross-shore CBL velocity gradients predicted solely by bottom boundary layer effects are much weaker than those observed in the field.

\section{Contributions from other stresses}

Bottom drag is of course only one of several factors influencing the balance of alongshore momentum in the coastal zone. A more complete evaluation of forcing terms would include bottom, lateral, and surface stresses, acceleration, an alongshore pressure gradient, as well as buoyancy, rotational, and wave-driven effects. Characterizing the CBL with this level of detail is beyond the scope of the present study, as the requisite data are not available. However, we can focus on those terms that should be most important to the general case of alongshore momentum balance in the CBL.

The conceptual model of the CBL is a well-mixed, quasi-steady, alongshore-uniform sheared flow within the order of a kilometer from shore, remote from major topographic features and their associated flow disruptions. Rotational, buoyancy, and acceleration terms are assumed to be negligible. Wave effects are also neglected given that wave-driven components of alongshore movement outside the surf zone are typically much smaller than those attributed to wind and alongshore pressure gradients (Lentz \& Fewings 2012). The CBL is bounded some distance offshore by a 'free stream' alongshore flow forced by an alongshore pressure gradient and surface wind stress. Within the CBL, water is subject to the drag of the coast and bottom in addition to pressure and wind forcing. Additional momentum transfer occurs through lateral mixing across the sheared alongshore flow. This representation of the CBL, as well as its logarithmic form, are not expected to hold in or very near the surf zone where wave forcing is significant; indeed, one may interpret $y_{0}$ as the width of the nearshore zone dominated by other phenomena (with the scale of wave-driven and/or topographic features) and thus is excluded from this simplified momentum balance.

Within the logarithmic region of the $\mathrm{CBL}$, the steady alongshore momentum balance can be modeled as the sum of the alongshore pressure gradient, 
surface wind stress, bottom stress, and lateral stress divergence, terms which have been shown to contribute to the momentum balance over the inner shelf (Lentz et al. 1999, Kirincich \& Barth 2009, Lentz \& Fewings 2012):

$$
\frac{1}{\rho} \frac{\partial P}{\partial x}+\frac{\tau_{s}}{\rho h}+\frac{\tau_{b}}{\rho h}+\frac{\partial \overline{u^{\prime} V^{\prime}}}{\partial y}=0
$$

where $\frac{\partial P}{\partial x}$ is the alongshore pressure gradient, $\tau_{\mathrm{s}}$ is the surface wind stress, and $\tau_{\mathrm{b}}$ is the bottom stress. The final term of Eq. (8) is the depth-averaged lateral stress divergence and represents the cross-shore gradient of the cross-shore flux of alongshore momentum, where lateral stress is the time-averaged product of the alongshore and cross-shore velocity fluctuations ( $u^{\prime}$ and $v^{\prime}$, respectively). Although the divergence term is rarely measured and therefore difficult to parameterize, it can be estimated from the other terms in the momentum balance:

$$
-\frac{\partial \overline{u^{\prime} V^{\prime}}}{\partial y}=\frac{1}{\rho} \frac{\partial P}{\partial x}+\frac{\tau_{s}}{\rho y \tan \alpha}+\frac{\tau_{b}}{\rho y \tan \alpha}
$$

where the quantity $y \tan \alpha$ has now replaced $h$ to account for the sloping seabed and to convert depth to distance from shore. In practice, the lateral stress divergence is often small enough to be omitted from the alongshore momentum balance (e.g. Lentz \& Winant 1986). It is important to note, however, that while the divergence may indeed be small and thereby imply a near-constant lateral stress, this stress could potentially be large. The existence of a finite lateral stress would contribute substantially to the establishment of observed patterns of velocity within the CBL, much as it does in traditional boundary layers where $\tau \neq 0$.

\section{Reconciling the logarithmic profile}

The momentum balance described by Eqs. (8) \& (9) is more complex than that underlying a standard, 1-dimensional logarithmic boundary layer. Yet, the CBL appears to adhere surprisingly well to the logarithmic functional form. Although the origins of this correspondence are not clear, and cannot fully be evaluated given data limitations, we offer a tentative analysis as a preliminary exploration of CBL structure.

Two linked factors are responsible for the logarithmic character of 1-dimensional turbulent boundary layers: constant cross-shore transfer of alongshore momentum (i.e. constant lateral stress) and a lateral mixing profile, or eddy viscosity, that increases linearly with distance from the boundary. Neither of these features is likely to hold exactly in the CBL case. On the other hand, it is possible that the complicated form of Eq. (9) reduces - at least approximately - to a simpler relationship once values for various terms are incorporated into the momentum balance.

To begin to evaluate this possibility, we conduct a rough evaluation of Eq. (9) across a range of distances from shore, $y$. As it is not possible to accurately quantify the full suite of forcing terms at all locations at all of our sites, we focus on an exemplar site (Terrace Point) where we have the best data and CBL assumptions are most defendable. We acknowledge that this is a site-specific analysis, which reduces the generality of any conclusions, but use it as an illustration and by virtue of a common pattern suggest that common dynamics are found at other sites. We assume an alongshore pressure gradient and wind stress that are constant with distance from shore. Based on published descriptions of nearshore dynamics off the coast of California (Hickey et al. 2003), we employ a typical value of $1 \times 10^{-4} \mathrm{~Pa} \mathrm{~m}^{-1}$ for a week-long average pressure gradient, and estimate alongshore surface wind stress from wind data collected just onshore of the ADCP transect at Terrace Point using a quadratic drag law (Large \& Pond 1981), which yields a week-long average wind stress of $1.42 \times 10^{-2} \mathrm{~Pa}$. Bottom stress is estimated from $\tau_{b}(y)=\rho r c U$, where $r$ is a linear drag coefficient $(5 \times$ $10^{-4}$; Lentz \& Winant 1986) and $c U$ is an estimate of the average bottom velocity, computed by multiplying the depth-averaged current velocity by the slope, $C$, of the linear regression between depth-averaged and bottom velocities ( $c=0.2$ for Terrace Point).

Of particular interest is whether lateral stress in the CBL is approximately constant across its width, as in a traditional logarithmic boundary layer, or whether it increases or decreases toward the shore. Recognizing that $-\rho \overline{u^{\prime} v^{\prime}}$ defines the lateral stress, $\tau_{\text {lat, }}$ and using $U$ from Eq. (2), Eq. (9) can be integrated to yield (see Appendix 2):

$$
\tau_{\text {lat }}(y)=\frac{\partial P}{\partial x} y+\frac{\tau_{s} \ln y}{\tan \alpha}+\frac{\rho r C U^{*} \mathrm{CBL}}{2 \kappa \tan \alpha}\left[\ln \left(\frac{y}{y_{0}}\right)\right]^{2}+D
$$

where $D$ is an integration constant that can be estimated from data of previous studies. Drifter deployments in northern California (Davis 1985) indicate that $\rho \overline{u^{\prime} v^{\prime}}$ declines toward the coast, reaching a value of $4 \mathrm{~Pa}$ at $1600 \mathrm{~m}$ from shore. Kirincich \& Barth (2009) present a stress divergence value of $0.1 \times 10^{-5} \mathrm{~m} \mathrm{~s}^{-2}$ at a distance of $1000 \mathrm{~m}$ over a week-long period, suggesting a lateral stress of the order of $1 \mathrm{~Pa}$. We there- 


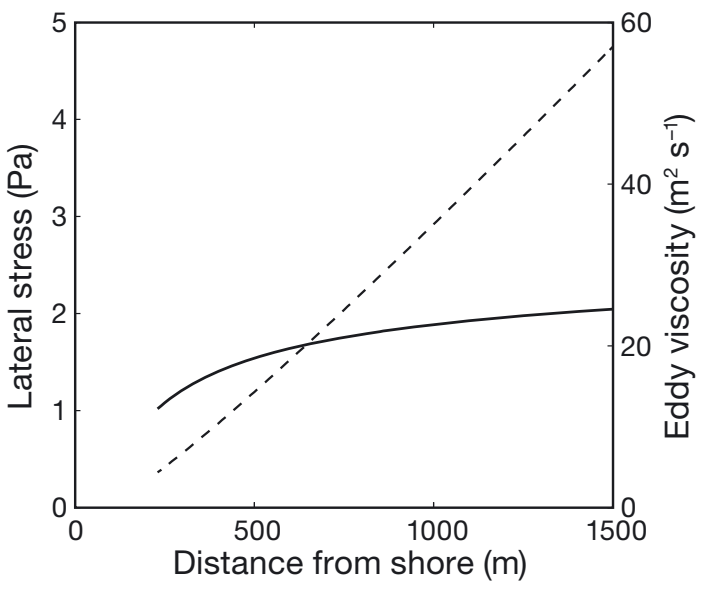

Fig. 8. Profiles of lateral stress (left axis; solid line) and eddy viscosity (right axis; dashed line) as a function of distance from shore at Terrace Point based on a rudimentary scaling analysis from the alongshore momentum balance in the coastal boundary layer (CBL)
Over the outer $80 \%$ of the CBL, which is the domain spanned by the logarithmic portion of the CBL, the lateral stress increases relatively slowly given the baseline parameter values from Terrace Point (Fig. 8, left axis). This pattern also holds across a substantially broader range of forcing conditions (Fig. 9). Ratios of maximum to minimum stress in the outer $80 \%$ of the CBL fall between 0.8 and 1.5, and cross-shore gradients in lateral stress are near zero, for all decreased pressure gradients as well as for pressure gradients increased by over $350 \%$ (Fig. 9A,D). Lateral stress profiles also remain similarly flat for wind stress adjustments as large as +35 or $-15 \%$ (Fig. 9B,E), and for changes to the bottom drag coefficient as substantial as +280 or $-40 \%$ (Fig. 9C,F). Importantly, the lateral stress across this spectrum of forcing conditions is never the smallest of the terms within Eq. (10), although the divergence in stress is close to zero.

\section{Estimates of horizontal eddy viscosity}

fore develop an order of magnitude estimate of $D$ by solving Eq. (10) with lateral stress set to $1 \mathrm{~Pa}$ at a distance of $y_{0}=225 \mathrm{~m}$ from shore, yielding $D=-3.11$.

With $D$ and thus the complete expression of Eq. (10) in hand, we can then examine the shape of the lateral stress profile as a function of distance from shore.
In the traditional derivation of a logarithmic boundary layer, a uniform lateral stress is accompanied by a linear eddy viscosity. Although limitations of the eddy viscosity concept for representing mixing are
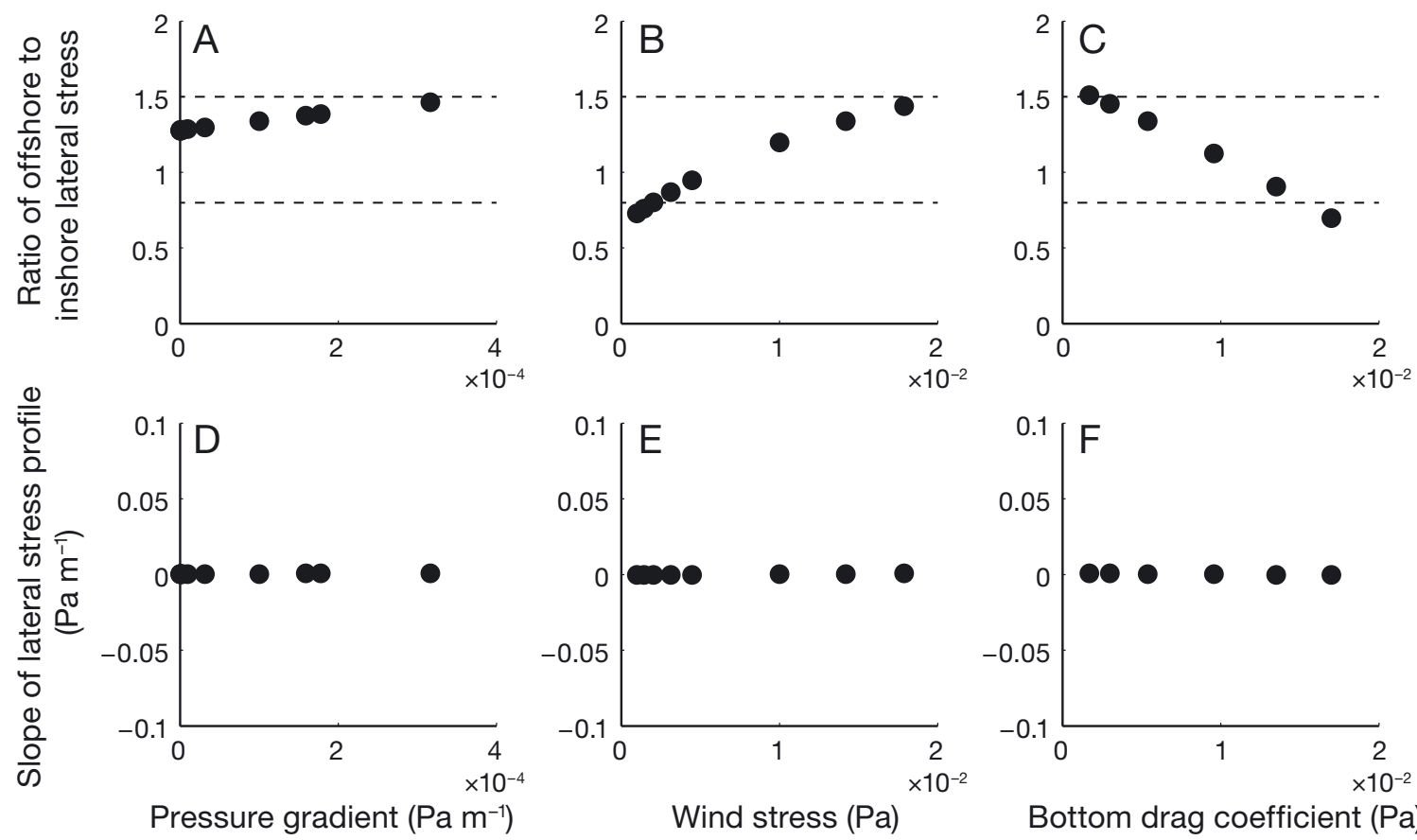

Bottom drag coefficient $(\mathrm{Pa})$

Fig. 9. Evaluation of the sensitivity of the cross-shore pattern of lateral stress to alternative forcing conditions. Ratio of offshore to inshore lateral stress observed in the outer $80 \%$ of the coastal boundary layer (CBL), as a function of (A) alongshore pressure gradient, (B) wind stress, or (C) bottom drag coefficient. Over substantial ranges of forcing conditions, values of this ratio fall between 0.8 and 1.5, as indicated by the dashed lines. Corresponding slopes of the lateral stress profiles (D-F) as a function of the same ranges in forcing. The cross-shore gradients in stress are universally near zero 
well known, it is a commonly used and convenient construct for describing horizontal dispersion of larvae or other biological particles (Jackson \& Strathmann 1981, Gaines et al. 2003, Largier 2003). We therefore rely on it here for our rudimentary scaling analysis of the CBL, and proceed to explore whether it approximates a linear dependence on distance from the shore.

Building on our evaluation of the lateral stress, we note the definitional expression (analogous to Eq. 6) that relates lateral stress, eddy viscosity and the CBL velocity gradient:

$$
\tau_{\text {lat }}=\rho K_{y} \frac{d U}{d y}
$$

From our field data, we know that velocities increase according to the logarithmic form described by Eq. (2), the derivative of which is:

$$
\frac{\mathrm{d} U}{\mathrm{~d} y}=\frac{U{ }^{*} \mathrm{CBL}}{\kappa} \frac{1}{y}
$$

The latter expression can be inserted into Eq. (11). The combination of Eqs. (11) \& (12) can in turn be merged with Eq. (10) to produce an explicit expression for the eddy viscosity profile in the CBL:

$$
K_{y}(y)=\frac{\kappa}{\rho U_{* \mathrm{CBL}}} y\left[\frac{\partial P}{\partial x} y+\frac{\tau_{s}}{\tan \alpha} \ln y+\frac{\rho r U_{* \mathrm{CBL}} C}{2 \kappa \tan \alpha}\left(\ln \frac{y}{y_{0}}\right)^{2}+D\right]
$$

Although the nature of the dependence of $K_{y}$ on distance from shore is not immediately apparent by inspection, a plot of Eq. (13) using the forcing parameters identified for Terrace Point indicates that $K_{y}$ follows a roughly linear trajectory (Fig. 8, right axis). This trend is also robust to variation in forcing. Conducting the same sensitivity analysis employed for the lateral stress (i.e. pressure gradient increased by $+350 \%$, wind stress altered +35 or $-15 \%$, and drag coefficient changed +280 or $-40 \%$ ) reveals only modest deviations from linear. Indeed, least squares parameter fits of the simple expression $K_{y}(y)=a y^{d}$ to plots of Eq. (13) indicate relatively constrained values of $a$ and $d$, with $d$ in particular ranging between 0.8 and 1.4. Such a nearly linearly increasing profile of horizontal eddy viscosity is also consistent with previous empirical estimates. For example, drifter studies off the coast of Northern California within $60 \mathrm{~km}$ from shore suggest $d \sim 1$ (Davis 1985) and dye studies from various regions suggest $1<d<1.5(d=1.33$, Stommel 1949; $d=1.1$, Okubo 1971).

Similar to the slopes of the viscosity profiles, values of $K_{Y}$ computed from Eq. (13) (Fig. 8) are also within the range of measured $K_{Y}$ from other studies. Off north-central California, Lagrangian surface drifter tracks within $60 \mathrm{~km}$ from shore suggest $K_{Y} \sim 16 \mathrm{~m}^{2} \mathrm{~s}^{-1}$ when interpolated to $2 \mathrm{~km}$ from shore using a linear model for eddy viscosity (Davis 1985). List et al. (1990) report values of 10 to $20 \mathrm{~m}^{2} \mathrm{~s}^{-1}$ at a distance of $2.6 \mathrm{~km}$ from shore off southern California from drogue and current meter data. Drake \& Edwards (2009) showed a close correspondence between model simulations of particle diffusion and measured float dispersion when using a linear model for $K_{y}$ that yielded a value of $60 \mathrm{~m}^{2} \mathrm{~s}^{-1}$ at $2 \mathrm{~km}$ from shore. At a distance of $2 \mathrm{~km}$ from shore (off Terrace Point), our analysis gives a $K_{y}$ of $83 \mathrm{~m}^{2} \mathrm{~s}^{-1}$, which is modestly larger than, but of the same order of magnitude as, the empirical measurements.

\section{Implications of the CBL for dispersal}

The well-defined structure of the CBL — including both its logarithmic velocity gradient and near-linear eddy viscosity profile-will substantially alter predicted dispersal distributions for larvae, algal spores, and/or other commodities suspended in the water column. We assume that diffusion of larvae and spores operates akin to diffusion of momentum, and therefore use our values of eddy viscosity to represent eddy diffusivity, a quantity more properly identified with mixing of water-borne material. We illustrate CBL consequences through the use of a 2-dimensional random-walk dispersal model (White et al. 2010b). We track simulated larvae considering 3 model cases. The base case represents the absence of a CBL, as in contemporary ecological models, by employing a spatially invariant alongshore velocity and a spatially invariant horizontal eddy diffusivity $\left(U=0.075 \mathrm{~m} \mathrm{~s}^{-1}, K_{Y}=40 \mathrm{~m}^{2} \mathrm{~s}^{-1}\right)$. The second case retains the same invariant eddy diffusivity, but introduces weaker nearshore velocities represented by a logarithmic velocity profile typical of a CBL, using $U_{{ }^{*} \mathrm{CBL}}$ and $y_{0}$ parameters from Terrace Point. These parameters result in a velocity of $0.075 \mathrm{~m} \mathrm{~s}^{-1}$ at the outer edge of the CBL $(y=1100 \mathrm{~m})$. The final case combines the logarithmic CBL profile from Terrace Point with reduced mixing nearshore, represented by the eddy diffusivity profile from this site $\left(K_{y}=5.92 \times\right.$ $10^{-3} y^{1.26}$, which reaches $40 \mathrm{~m}^{2} \mathrm{~s}^{-1}$ at the edge of the CBL).

In conducting these simulations, larvae were released at a distance $y_{0}=225 \mathrm{~m}$ from the shore, to model a shallow subtidal organism spawning near the outside edge of the surf zone. Most marine larvae 
are developmentally incapable of settling for some time after release, during a period typically termed a 'precompetency window.' After passing through this window, they then enter a 'competency window' of similar duration (Jackson \& Strathmann 1981, Gaylord \& Gaines 2000), during which they can settle if they encounter suitable habitat. Simulations were conducted with precompetency and competency windows set to $5 \mathrm{~d}$ to mimic species with brief pelagic larval durations, such as the red abalone Haliotis rufescens of the west coast of North America (Haaker et al. 2001). Settling larvae were counted as those that returned to within $225 \mathrm{~m}$ from shore during the competency window. While behavioral capabilities (e.g. vertical positioning or horizontal swimming) can clearly influence the dispersal of some larvae (Leis 2006, Shanks \& Shearman 2009, Morgan \& Fisher 2010 ), the goal of this model was to illustrate the potential impacts of velocity gradients alone on dispersal outcomes, and we treat larvae as passive particles.

Results of the simulations indicate strong potential effects of the CBL on larval dispersal. The incorporation of a logarithmic velocity profile and spatially variable eddy diffusivity decreased predicted mean transport by $10 \%$, from 40 to $36 \mathrm{~km}$ (Fig. 10) and caused a $10 \%$ increase in the standard deviation of transport distance. These effects arose because slowed nearshore velocities reduce net displacement, while slowed mixing across the velocity gradient broadens the alongshore distribution through enhanced shear dispersion, causing larvae to be advected at different rates downstream depending on their cross-shore position.

Perhaps even more important are predicted effects of the CBL on settlement and self-replenishment, the latter defined here as the proportion of settling propagules returning to within $10 \mathrm{~km}$ of the source site. Incorporating a CBL velocity gradient and a linearly increasing eddy diffusivity resulted in an $18 \%$ decrease in total settlement but a $1000 \%$ increase in self-replenishment. These effects arose because as diffusivities decrease closer to shore, horizontal mixing motions become smaller and the return to suitable habitat takes longer, which makes it more difficult for larvae to be mixed back toward shoreline habitat. In addition, a small diffusivity near the shore results in some larvae remaining very close to their site of origin (see distances of -10 to $10 \mathrm{~km}$ in Fig. 10).

Slower flows near the coast, and the resultant decrease in alongshore transport, likely add to a suite of physical processes affecting dispersal and recruitment. Although other mechanisms for the local

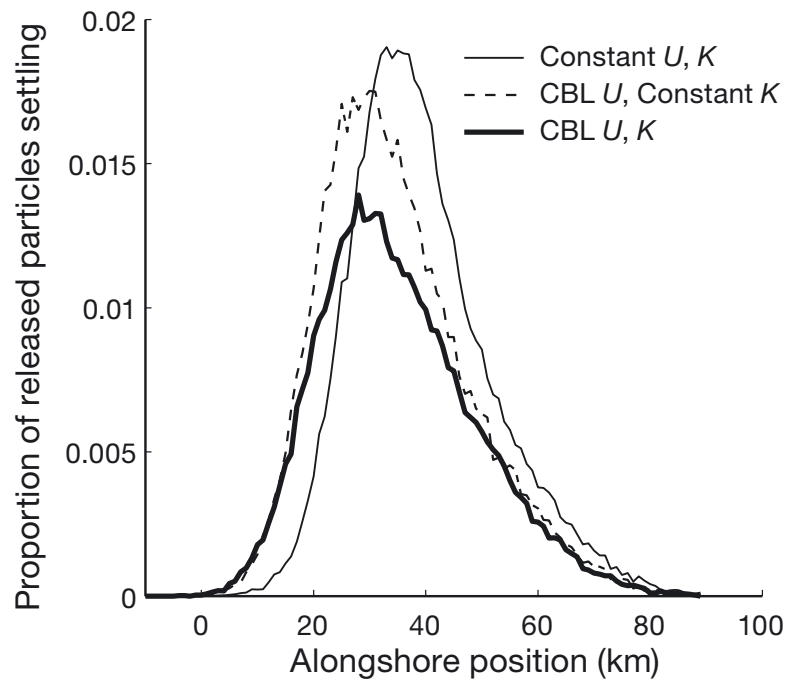

Fig. 10. Dispersal kernels generated from a 2-dimensional random walk model with different assumptions about the existence and/or properties of the coastal boundary layer (CBL). Case 1 (solid light line) incorporates constant alongshore velocity, $U,\left(0.075 \mathrm{~m} \mathrm{~s}^{-1}\right)$ and constant horizontal eddy diffusivity, $K_{Y^{\prime}}\left(40 \mathrm{~m}^{2} \mathrm{~s}^{-1}\right)$. Case 2 (dashed line) incorporates the logarithmic velocity profile similar to that at Terrace Point but retains the constant eddy diffusivity. Case 3 (solid dark line) incorporates a full CBL, with both a logarithmic velocity gradient and linearly increasing eddy diffusivity, using parameter values similar to those observed at Terrace Point. Lines are fits through histograms partitioned into $1 \mathrm{~km}$ bins

return of dispersers have been invoked previously (as in the case of headland or island wakes; e.g. Wing et al. 1995, Graham \& Largier 1997, Swearer et al. 1999), most are location- or time-specific. By contrast, the CBL structure described here is expected to be ubiquitous, deriving from unavoidable velocity shear near the coast. Consequences of the CBL may also be non-trivial, given its strong effects on the degree to which populations could self-seed. Indeed, the CBL may result in substantially tighter coupling between local production and recruitment, even in the absence of other identifiable agents of retention, or potentially in synergy with them (e.g. Sponaugle et al. 2002). Thus, although larval behavior has routinely been invoked as a key element increasing the return of larvae to their sites of origin, and is surely important, a potentially equally important factor valid also for passive or near-passive larvae is the retention of organisms in slower flows in the inner portion of the CBL. Nearshore flow rates have already been shown empirically to affect recruitment rates of coastal marine invertebrates, with higher recruitment arising in cases of long residence times of water masses (Gaines \& Bertness 1992). The present 
study reiterates the well-recognized connection between coastal processes and population dynamics of shoreline organisms.

There is also strong potential for interaction of larval behavior with the CBL. Although our modeling efforts focus exclusively on physical processes in dispersal and do not address behavior in any detail, the capacity for larval swimming to influence transport is well recognized. Efforts to merge behavioral models with higher-resolution representations of nearshore currents could therefore provide valuable insights in future studies.

\section{Application of the CBL to circulation studies}

Most circulation-resolving dispersal models do not account for small-scale spatial variations in velocity and mixing near to the coast, even though these variations may be of first-order importance for populations that spawn and recruit along the shoreline or in the nearshore habitats. However, incorporating more realistic nearshore flow properties in models for dispersal and population dynamics, even in simple advection-diffusion approaches, can change predictions appreciably (Aiken et al. 2007, White et al. 2010a,b). In addition, existing numerical circulation models use a variety of boundary conditions (e.g. noslip or free slip; Aiken et al. 2007, Mitarai et al. 2009). The CBL pattern described here may provide more explicit rationale for certain choices. It may also facilitate interpolation of remote-sensing data to shore (e.g. high-frequency radar maps of surface currents, e.g. Kaplan \& Largier 2006), closing an important information gap in existing dispersal models that are increasingly used to estimate population connectivity. Our statements concerning such efforts are not intended, of course, to imply that they are straightforward. Results presented above emerge from a 2dimensional approach to understanding nearshore transport, and therefore represent only a first step at describing the general flow structure within the CBL. Significant hurdles remain, particularly in cases where effects of larval behavior and/or vertical variation in currents are factors of interest.

\section{Further considerations for the CBL}

Although our coastal velocity profiles were all quantified during the summer season, making extrapolation to other times of year difficult, we expect the most basic elements of the CBL to apply quite gener- ally. Offshore velocities may change in response to season (e.g. the strength of the offshore California Current), but velocities inshore will still be influenced by the frictional effects of the shore. Such a link is clearly evident in the longer record at Huntington Beach, which included changes in the direction of shelf-scale flow, but which was also characterized consistently by a robust CBL.

The level of nearshore flow attenuation described here may be a conservative estimate in certain circumstances, due to the potential for coastal currents to interact with more pronounced drag elements like elevated reefs or dense vegetation. All our instruments were deliberately placed away from such elements, but their effects can be large. For example, alongshore velocities within kelp forests may be as low as $50 \%$ of speeds outside (Jackson \& Winant 1983, Gaylord et al. 2007, 2012, Rosman et al. 2007). Seagrass beds and mangroves are likely to have similar effects (e.g. Fonseca et al. 1982). Even in the absence of such additional flow attenuation, coastal boundary layers have clear potential to reduce alongshore transport of larvae, spores, and other suspended materials. Although these and other complexities of the coastal ocean do not lend themselves to simultaneously simple and complete representations, the straightforward parameterizations identified here provide a useful construct for conceptualizing and predicting consequences of nearshore velocity structure.

Acknowledgements. We thank D. Reed, C. Nelson, S. Harrer, K. Aquilino, D. Dann, L. Garske, A. Hettinger, S. Miller, M. Sheridan, W. Dowd, M. Boller, M. Foley, and B. Mahoney for field assistance. J. W. White assisted with the particletracking model, and S. G. Monismith, C. A. Edwards, M. Fewings, and S. J. Lentz provided helpful feedback. This work was funded by NSF grants OCE-927255 and OCE1065990, and by the University of California Marine Council Coastal Environmental Quality Initiative grants 04-T-CEQI08-0048 and 07-T-CEQI-10-0060. K.J.N. was supported by a Bodega Marine Laboratory Graduate Student Fellowship, a Jastro Shields Research Scholarship, and funds from the University of California at Davis Graduate Group in Ecology. Subsets of data were provided by the Partnership for Interdisciplinary Studies of Coastal Oceans (PISCO) and the Orange County Sanitation District (OCSD).

\section{LITERATURE CITED}

Aiken CM, Navarrete SA, Castillo MI, Castilla JC (2007) Along-shore larval dispersal kernels in a numerical ocean model of the central Chilean coast. Mar Ecol Prog Ser 339: $13-24$

Bassin CJ, Washburn L, Brzezinski M, McPhee-Shaw E (2005) Sub-mesoscale coastal eddies observed by high frequency radar: A new mechanism for delivering nutri- 
ents to kelp forests in the Southern California Bight. Geophys Res Lett 32, L,12604, doi:10.1029/2005GL 023017

Becker BJ, Levin LA, Fodrie FJ, McMillan PA (2007) Complex larval connectivity patterns among marine invertebrate populations. Proc Natl Acad Sci 104:3267-3272

Borges R, Ben-Hamadou R, Chicharo MA, Re P, Goncalves EJ (2007) Horizontal spatial and temporal distribution patterns of nearshore larval fish assemblages at a temperate rocky shore. Estuar Coast Shelf Sci 71:412-428

Caley MJ, Carr MH, Hixon MA, Hughes TP, Jones GP, Menge BA (1996) Recruitment and the local dynamics of open marine populations. Annu Rev Ecol Syst 27:477-500

Churchill JH (1985) Properties of flow within the coastal boundary layer off Long Island, New York. J Phys Oceanogr 15:898-916

Clarke LB, Ackerman D, Largier J (2007) Dye dispersion in the surf zone: measurements and simple models. Cont Shelf Res 27:650-669

> Cowen RK (1985) Large-scale pattern of recruitment by the Labrid, Semicossyphus pulcher: causes and implications. J Mar Res 43:719-742

> Cowen RK, Sponaugle S (2009) Larval dispersal and marine population connectivity. Annu Rev Mar Sci 1:443-466

> Csanady GT (1972) The coastal boundary layer in Lake Ontario: Part II. The summer-fall regime. J Phys Oceanogr 2:168-176

$>$ Davis RE (1985) Drifter observations of coastal surface currents during CODE: the statistical and dynamical views. J Geophys Res C 90:4756-4772

Denny MW (1988) Biology and the mechanics of the waveswept environment. Princeton University Press, Princeton, NJ

> Drake PT, Edwards CA (2009) A linear diffusivity model of near-surface, cross-shore particle dispersion from a numerical simulation of central California's coastal ocean. J Mar Res 67:385-409

- Eckman JE (1990) A model of passive settlement by planktonic larvae onto bottoms of differing roughness. Limnol Oceanogr 35:887-901

> Fewings M, Lentz SJ, Fredericks J (2008) Observations of cross-shelf flow driven by cross-shelf winds on the inner continental shelf. J Phys Oceanogr 38:2358-2378

Fonseca MS, Fisher JS, Zieman JC, Thayer GW (1982) Influence of the seagrass, Zostera marina L., on current flow. Estuar Coast Shelf Sci 15:351-364

> Gaines SD, Bertness MD (1992) Dispersal of juveniles and variable recruitment in sessile marine species. Nature 360:579-580

> Gaines SD, Brown S, Roughgarden J (1985) Spatial variation in larval concentrations as a cause of spatial variation in settlement for the barnacle, Balanus glandula. Oecologia 67:267-272

Gaines SD, Gaylord B, Largier JL (2003) Avoiding current oversights in marine reserve design. Ecol Appl 13(Suppl): 32-46

Gawarkiewicz G, Monismith SG, Largier JL (2007) Observing larval transport processes affecting population connectivity: progress and challenges. Oceanography 20: 40-53

> Gaylord B, Gaines SD (2000) Temperature or transport? Range limits in marine species mediated solely by flow. Am Nat 155:769-789

Gaylord B, Reed D, Raimondi PT, Washburn L, McLean S (2002) A physically based model of macroalgal spore dis- persal in the wave and current-dominated nearshore. Ecology 83:1239-1251

Gaylord B, Reed D, Raimondi PT, Washburn L (2006) Macroalgal spore dispersal in coastal environments: mechanistic insights revealed by theory and experiment. Ecol Monogr 76:481-502

> Gaylord B, Rosman JH, Reed DC, Koseff JR and others (2007) Spatial patterns of flow and their modification within and around a giant kelp forest. Limnol Oceanogr 52:1838-1852

Gaylord, B, Nickols KJ, Jurgens L (2012) Roles of transport and mixing processes in kelp forest ecology. J Exp Biol 215:997-1007

- Graham W, Largier JL (1997) Upwelling shadows as nearshore retention sites: the example of northern Monterey Bay. Cont Shelf Res 17:509-532

> Grant WD, Madsen OS (1986) The continental-shelf bottom boundary layer. Annu Rev Fluid Mech 18:265-305

Haaker P, Karpov K, Rogers-Bennett L, Taniguchi I, Friedman CS, Tegner MJ (2001) Abalone. In: Leet WS, Dewees CM, Klingbeil R, Larson EJ (eds) California's living marine resources: a status report. California Department of Fish and Game, Sacramento, CA, p 89-97

Hamilton P, Noble MA, Largier JL, Rosenfeld LK, Robertson G (2006) Cross-shelf subtidal variability in San Pedro Bay during summer, 2001. Cont Shelf Res 26:681-702

Hellberg ME, Burton RS, Neigel JE, Palumbi SR (2002) Genetic assessment of connectivity among marine populations. Bull Mar Sci 70:273-290

> Hickey BM, Dobbins EL, Allen SE (2003) Local and remote forcing of currents and temperature in the central Southern California Bight. J Geophys Res 108:3081-3106

> Jackson GA, Strathmann RR (1981) Larval mortality from offshore mixing as a link between pre-competent and competent periods of development. Am Nat 118:16-26

> Jackson GA, Winant CD (1983) Effect of a kelp forest on coastal currents. Cont Shelf Res 2:75-80

> Jones GP, Planes S, Thorrold SR (2005) Coral reef fish larvae settle close to home. Curr Biol 15:1314-1318

> Jones GP, Almany GR, Russ GR, Sale PF, Steneck RS, van Oppen MJH, Willis BL (2009) Larval retention and connectivity among populations of corals and reef fishes: history, advances and challenges. Coral Reefs 28: 307-325

> Kaplan DM, Largier JL (2006) HF radar-derived origin and destination of surface waters off Bodega Bay, California. Deep-Sea Res II 53:2906-2930

Kirincich AR, Barth JA (2009) Alongshelf variability of innershelf circulation along the Central Oregon coast during summer. J Phys Oceanogr 39:1380-1398

Large WG, Pond S (1981) Open ocean momentum flux measurements in moderate to strong winds. J Phys Oceanogr 11:324-336

Largier JL (2002) Linking oceanography and nearshore ecology: perspectives and challenges. In: Castilla J, Largier JL (eds) The oceanography and ecology of the nearshore and bays in Chile. Universidad Catolica de Chile, Santiago, p 207-239

Largier JL (2003) Considerations in estimating larval dispersal distances from oceanographic data. Ecol Appl 13(Suppl):71-89

Leis JM (2006) Are larvae of demersal fishes plankton or nekton? Adv Mar Biol 51:57-141

Lentz SJ (1994) Current dynamics over the northern California inner-shelf. J Phys Oceanogr 24:2461-2478 
Lentz SJ, Fewings MR (2012) The wind- and wave-driven inner-shelf circulation. Annu Rev Mar Sci 4:317-343

> Lentz SJ, Winant CD (1986) Subinertial currents on the Southern California shelf. J Phys Oceanogr 16:1737-1750

> Lentz SJ, Guza RT, Elgar S, Feddersen F, Herbers THC (1999) Momentum balances on the North Carolina inner shelf. J Geophys Res C 104:18205-18226

- Levin LA (2006) Recent progress in understanding larval dispersal: new directions and digressions. Integr Comp Biol 46:282-297

Lewin R (1986) Supply-side ecology. Science 234:25-27

List EJ, Gartrell G, Winant CD (1990) Diffusion and dispersion in coastal waters. J Hydraul Eng 116:1158-1179

MacMahan J, Brown J, Brown J, Thornton E and others (2010) Mean Lagrangian flow behavior on an open coast rip-channeled beach: A new perspective. Mar Geol 268: $1-15$

> Mitarai S, Siegel DA, Watson JR, Dong C, McWilliams JC (2009) Quantifying connectivity in the coastal ocean with application to the Southern California Bight. J Geophys Res C 114, C10026, doi:10.1029/2008JC005166

- Morgan SG, Fisher JL (2010) Larval behavior regulates nearshore retention and offshore migration in an upwelling shadow and along the open coast. Mar Ecol Prog Ser 404:109-126

Morgan SG, Fisher JL, Miller SH, McAfee ST, Largier JL (2009) Nearshore larval retention in a region of strong upwelling and recruitment limitation. Ecology 90:3489-3502

Noble M, Xu J (2004) Huntington Beach shoreline contamination investigation, Phase III, final report: Coastal circulation and transport patterns: the likelihood of OCSD's plume impacting Huntington Beach shoreline. USGS Open File Rep. 2004-1019

Ohlmann JC, Mitarai S (2010) Lagrangian assessment of simulated surface current dispersion in the coastal ocean. Geophys Res Lett 37, L17602, doi:10.1029/2010GL044436

Okubo A (1971) Oceanic diffusion diagrams. Deep-Sea Res 18:789-802

Paduan JD, Rosenfeld LK (1996) Remotely sensed surface currents in Monterey Bay from shore-based HF-radar (Coastal Ocean Dynamics Application Radar). J Geophys Res C 101:20669-20686

Palumbi SR (2004) Marine reserves and ocean neighborhoods: The spatial scale of marine populations and their management. Annu Rev Environ Resour 29:31-68

> Paris CB, Cherubin LM, Cowen RK (2007) Surfing, spinning, or diving from reef to reef: effects on population connectivity. Mar Ecol Prog Ser 347:285-300

Rasmussen LL, Cornuelle BD, Levin LA, Largier JL, Di Lorenzo E (2009) Effects of small-scale features and local wind forcing on tracer dispersion and estimates of population connectivity in a regional scale circulation model. J Geophys Res C 114, C01012, doi:10.1029/2008JC004777

Rosenfeld LK (1983) CODE-1: Moored array and large-scale data report. Woods Hole Oceanogr Inst Tech Rep WHOI83-23

Rosman JH, Koseff JR, Monismith SG, Grover J (2007) A field investigation into the effects of a kelp forest (Macrocystis pyrifera) on coastal hydrodynamics and transport. J Geophys Res C 112, C02016, doi:10.1029/2005JC003430

> Roughgarden J, Gaines SD, Possingham H (1988) Recruitment dynamics in complex life-cycles. Science 241:1460-1466

Schlicting H (1979) Boundary-layer theory. McGraw-Hill, New York, NY

Shanks AL (2009) Pelagic larval duration and dispersal distance revisited. Biol Bull 216:373-385

Shanks AL, Shearman RK (2009) Paradigm lost? Cross-shelf distributions of intertidal invertebrate larvae are unaffected by upwelling or downwelling. Mar Ecol Prog Ser 385:189-204

Siegel DA, Kinlan BP, Gaylord B, Gaines SD (2003) Lagrangian descriptions of marine larval dispersion. Mar Ecol Prog Ser 260:83-96

- Siegel DA, Mitarai S, Costello CJ, Gaines SD, Kendall BE, Warner RR, Winters KB (2008) The stochastic nature of larval connectivity among nearshore marine populations. Proc Natl Acad Sci 105:8974-8979

Sponaugle S, Cowen RK, Shanks A, Morgan SG and others (2002) Predicting self-recruitment in marine populations: biophysical correlates and mechanisms. Bull Mar Sci 70: 341-375

> Spydell MS, Feddersen F, Guza RT (2009) Observations of drifter dispersion in the surfzone: The effect of sheared alongshore currents. J Geophys Res C 114, C07028, doi: 10.1029/2009JC005328

Stommel H (1949) Horizontal diffusion due to oceanic turbulence. J Mar Res 8:199-225

Swearer SE, Caselle JE, Lea DW, Warner RR (1999) Larval retention and recruitment in an island population of a coral-reef fish. Nature 402:799-802

Swearer SE, Shima JS, Hellberg ME, Thorrold SR and others (2002) Evidence of self-recruitment in demersal marine populations. Bull Mar Sci 70:251-271

Thorrold SR, Zacherl DC, Levin LA (2007) Population connectivity and larval dispersal using geochemical signatures in calcified structures. Oceanography 20:80-89

Thorson G (1946) Reproduction and larval development of Danish marine bottom invertebrates. Medd Kom Dan Fisk Havunders Plankton 4:1-523

> Watson JR, Mitarai S, Siegel DA, Caselle JE, Dong C, McWilliams JC (2010) Realized and potential larval connectivity in the Southern California Bight. Mar Ecol Prog Ser 401:31-48

Werner FE, Cowen RK, Paris CB (2007) Coupled biological and physical models: present capabilities and necessary developments for future studies of population connectivity. Oceanography 20:54-69

> White JW, Botsford LW, Hastings A, Largier JL (2010a) Population persistence in marine reserve networks: incorporating spatial heterogeneities in larval dispersal. Mar Ecol Prog Ser 398:49-67

White JW, Nickols KJ, Clarke L, Largier JL (2010b) Larval entrainment in cooling water intakes: spatially explicit models reveal effects on benthic metapopulations and shortcomings of traditional assessments. Can J Fish Aquat Sci 67:2014-2031

Wiberg PL, Drake DE, Cacchione DA (1994) Sediment resuspension and bed armoring during high bottom stress events on the Northern California inner continental shelf: measurements and predictions. Cont Shelf Res 14:1191-1219

Winant CD, Dorman CE (1997) Seasonal patterns of surface wind stress and heat flux over the Southern California Bight. J Geophys Res 102:5641-5653

> Wing SR, Botsford LW, Largier JL, Morgan LE (1995) Spatial structure of relaxation events and crab settlement in the northern California upwelling system. Mar Ecol Prog Ser 128:199-211

Wolanski E (1992) Hydrodynamics of mangrove swamps and their coastal waters. Hydrobiologia 247:141-161 
Appendix 1. Depth-averaged velocity derivation via the 'law of the wall'

The depth-averaged velocity, $U_{\text {calc, }}$ at a cross-shore location, $y$, is equal to the integral of velocity via the law of the wall (Eq. 1), divided by depth, $h$ :

$$
U_{\text {calc }}(y)=\frac{1}{h} \int_{z_{0}}^{h} \frac{u_{*}}{\kappa} \ln \left(\frac{z}{z_{0}}\right) \mathrm{d} z
$$

This equation is rearranged to consider depth-averaged velocity as a function of distance from shore, rather than depth, by setting $h=y \tan \alpha$ :

$$
U_{\text {calc }}(y)=\frac{1}{y \tan \alpha} \int_{z_{0}}^{y \tan \alpha} \frac{u_{*}}{\kappa} \ln \left(\frac{z}{z_{0}}\right) \mathrm{d} z
$$

where $\alpha$ is the bathymetric slope.

Separating the quantity $\ln \left(\frac{z}{z_{0}}\right)$ yields:

$$
\begin{aligned}
& U_{\text {calc }}(y)=\frac{1}{y \tan \alpha} \int_{z_{0}}^{y \tan \alpha} \frac{u_{*}}{\kappa} \ln z \mathrm{~d} z-\frac{1}{y \tan \alpha} \int_{z_{0}}^{y \tan \alpha} \frac{u_{*}}{\kappa} \ln z_{0} \mathrm{~d} z \\
& U_{\text {calc }}(y)=\frac{u_{*}}{\kappa y \tan \alpha}\left(\int_{z_{0}}^{y \tan \alpha} \ln z \mathrm{~d} z-\int_{z_{0}}^{y \tan \alpha} \ln z_{0} \mathrm{~d} z\right)
\end{aligned}
$$

Integrating leads to:

$$
\begin{aligned}
& U_{\text {calc }}(y)=\frac{u_{*}}{\kappa y \tan \alpha}\left(z \ln z-z\left|\sum_{z_{0}}^{y \tan \alpha}-z \ln z_{0}\right|_{z_{0}}^{y \tan \alpha}\right) \\
& U_{\text {calc }}(y)=\frac{u_{*}}{\kappa y \tan \alpha}\left[\left(y \tan \alpha[\ln y \tan \alpha]-y \tan \alpha-\left[z_{0} \ln z_{0}-z_{0}\right]\right)-\left(y \tan \alpha \ln z_{0}-z_{0} \ln z_{0}\right)\right] \\
& U_{\text {calc }}(y)=\frac{u_{*}}{\kappa y \tan \alpha}\left[y \tan \alpha(\ln y \tan \alpha-1)-z_{0} \ln z_{0}+z_{0}-y \tan \alpha \ln z_{0}+z_{0} \ln z_{0}\right] \\
& U_{\text {calc }}(y)=\frac{u_{*}}{\kappa y \tan \alpha}\left[y \tan \alpha\left(\ln y \tan \alpha-1-\ln z_{0}\right)\right]+\frac{u_{*} z_{0}}{\kappa y \tan \alpha} \\
& U_{\text {calc }}(y)=\frac{u_{*}}{\kappa}\left(\ln y \tan \alpha-\ln z_{0}-1\right)+\frac{u_{*} z_{0}}{\kappa y \tan \alpha} \\
& U_{\text {calc }}(y)=\frac{u_{*}}{\kappa}\left[\ln \left(\frac{y \tan \alpha}{z_{0}}\right)-1\right]+\frac{u_{*} z_{0}}{\kappa y \tan \alpha}
\end{aligned}
$$

Appendix 2. Solution for lateral stress and eddy viscosity profiles from an alongshore momentum balance

The alongshore momentum balance within the coastal boundary layer is represented by the sum of the alongshore pressure gradient $\left(\frac{\partial P}{\partial x}\right)$, surface wind stress $\left(\tau_{\mathrm{s}}\right)$, bottom stress $\left(\tau_{\mathrm{b}}\right)$, and lateral stress divergence $\left(\frac{\partial \overline{u^{\prime} v^{\prime}}}{\partial y}\right)$, with $h=$ depth, $y=$ cross-shore distance, and $\rho=$ density: $\frac{1}{\rho} \frac{\partial P}{\partial x}+\frac{\tau_{s}}{\rho h}+\frac{\tau_{b}}{\rho h}+\frac{\partial \overline{u^{\prime} v^{\prime}}}{\partial y}=0$

Solving for the lateral stress divergence yields:

$$
-\frac{\partial \overline{u^{\prime} v^{\prime}}}{\partial y}=\frac{1}{\rho} \frac{\partial P}{\partial x}+\frac{\tau_{s}}{\rho h}+\frac{\tau_{b}}{\rho h}
$$

This equation is rearranged to consider stress divergence as a function of distance from shore, rather than depth, by setting $h=y \tan \alpha$ :

$$
-\frac{\partial \overline{u^{\prime} v^{\prime}}}{\partial y}=\frac{1}{\rho} \frac{\partial P}{\partial x}+\frac{\tau_{s}}{\rho y \tan \alpha}+\frac{\tau_{b}}{\rho y \tan \alpha}
$$

where $\alpha$ is the bathymetric slope. 
Appendix 2 (continued)

Multiplying both sides of Eq. (A13) by $\rho$ gives:

$-\frac{\partial \rho \overline{u^{\prime} v^{\prime}}}{\partial y}=\frac{\partial P}{\partial x}+\frac{\tau_{s}}{y \tan \alpha}+\frac{\tau_{b}}{y \tan \alpha}$

Lateral stress, $\tau_{\text {lat, }}$ is equal to $-\rho \overline{u^{\prime} V^{\prime}}$ :

$\frac{\partial \tau_{\text {lat }}}{\partial y}=\frac{\partial P}{\partial x}+\frac{\tau_{s}}{y \tan \alpha}+\frac{\tau_{b}}{y \tan \alpha}$

Bottom stress is estimated following a linear drag law:

$\tau_{b}=\rho r c U$

where $r$ is a linear drag coefficient, $U$ is depth-averaged velocity, and $c$ is a conversion factor between depth-averaged and bottom velocity, determined from a linear regression of depthaveraged velocity against bottom velocity from velocity records.

In the coastal boundary layer, velocity increases logarithmically with distance from shore:

$\frac{U(y)}{U_{* \mathrm{CBL}}}=\frac{1}{\kappa} \ln \left(\frac{y}{y_{0}}\right)$

Substituting Eq. (A17) into Eq. (A16) yields:

$\tau_{b}(y)=\rho r c \frac{U_{*^{*} \mathrm{CBL}}}{\kappa} \ln \left(\frac{y}{y_{0}}\right)$

Eq. (A15) then becomes:

$$
\frac{\partial \tau_{\text {lat }}}{\partial y}=\frac{\partial P}{\partial x}+\frac{\tau_{s}}{y \tan \alpha}+\frac{\rho r c U_{* \mathrm{CBL}}}{\kappa y \tan \alpha} \ln \left(\frac{y}{y_{0}}\right)
$$

The alongshore pressure gradient and wind stress remain constant with distance from shore. Integrating Eq. (A19) gives the function for lateral stress as a function of distance from shore: $\tau_{\text {lat }}(y)=\frac{\partial P}{\partial x} y+\frac{\tau_{s} \ln y}{\tan \alpha}+\frac{\rho r c U_{*_{\mathrm{CBL}}}}{2 \kappa \tan \alpha}\left[\ln \left(\frac{y}{y_{0}}\right)\right]^{2}+D$

where $D$ is an integration constant.

Lateral stress is related to eddy viscosity, $K_{y}$ by the following expression:

$\tau_{\text {lat }}=\rho K_{y} \frac{\mathrm{d} U}{\mathrm{~d} y}$

Rearranging to solve for $K_{Y}$ yields:

$K_{y}=\frac{\tau_{\text {lat }}}{\rho}\left(\frac{\mathrm{d} U}{\mathrm{~d} y}\right)^{-1}$

The velocity gradient, $\frac{\mathrm{d} U}{\mathrm{~d} y}$, is equal to the derivative of the depth-averaged velocity profile,
Eq. (A17): $\frac{\mathrm{d} U}{\mathrm{~d} y}=\frac{U_{* \mathrm{CBL}}}{\kappa} \frac{1}{y}$

Substituting Eqs. (A20) \& (A23) into Eq. (A22) gives the function for eddy viscosity as a function of distance from shore:

$$
K_{Y}(y)=\frac{\kappa}{\rho U_{*}{ } \mathrm{CBL}} y\left[\frac{\partial P}{\partial x} y+\frac{\tau_{s}}{\tan \alpha} \ln y+\frac{\rho r U_{*}{ }_{\mathrm{CBL}} C}{2 \kappa \tan \alpha}\left(\ln \frac{y}{y_{0}}\right)^{2}+D\right]
$$

Editorial responsibility: Romuald Lipcius,

Gloucester Point, Virginia, USA
Submitted: December 12, 2011; Accepted: June 12, 2012

Proofs received from author(s): September 6, 2012 